Florida International University

FIU Digital Commons

FIU Electronic Theses and Dissertations

University Graduate School

6-27-2019

\title{
Attentional Processes in Anxiety: Examining Threat-Related Attention Bias and Attentional Control in Anxious Youth
}

Raquel Melendez

Florida International University, rmelen@fiu.edu

Follow this and additional works at: https://digitalcommons.fiu.edu/etd

Part of the Child Psychology Commons, and the Clinical Psychology Commons

\section{Recommended Citation}

Melendez, Raquel, "Attentional Processes in Anxiety: Examining Threat-Related Attention Bias and Attentional Control in Anxious Youth" (2019). FIU Electronic Theses and Dissertations. 4232.

https://digitalcommons.fiu.edu/etd/4232

This work is brought to you for free and open access by the University Graduate School at FIU Digital Commons. It has been accepted for inclusion in FIU Electronic Theses and Dissertations by an authorized administrator of FIU Digital Commons. For more information, please contact dcc@fiu.edu. 


\title{
FLORIDA INTERNATIONAL UNIVERSITY
}

\author{
Miami, Florida
}

ATTENTIONAL PROCESSES IN ANXIETY: EXAMINING THREAT-RELATED ATTENTION BIAS

AND ATTENTIONAL CONTROL IN ANXIOUS YOUTH

A dissertation submitted in partial fulfillment of the

requirements for the degree of

DOCTOR OF PHILOSOPHY

in

PSYCHOLOGY

by

Raquel Melendez

2019 
To: Dean Michael R. Heithaus

College of Arts, Sciences, and Education

This dissertation, written by Raquel Melendez, and entitled Attentional Processes in Anxiety: Examining Threat-Related Attention Bias and Attentional Control in Anxious Youth, having been approved in respect to style and intellectual content, is referred to you for judgment.

We have read this dissertation and recommend that it be approved.

Daniel M. Bagner

Stefany Coxe

Andy Pham

Jeremy W. Pettit, Major Professor

Date of Defense: June 27, 2019

The dissertation of Raquel Melendez is approved.

Dean Michael R. Heithaus College of Arts, Sciences and Education

Andrés G. Gil

Vice President for Research and Economic Development and Dean of the University Graduate School

Florida International University, 2019 
(C) Copyright 2019 by Raquel Melendez

All rights reserved. 


\section{ACKNOWLEDGMENTS}

I would like to express my gratitude to my friends and family for their endless encouragement and to my committee members for their invaluable contributions to this project.

My deepest thanks to my mentor, Jeremy W. Pettit, for his unconditional support, guidance, and humor throughout this journey. 
ABSTRACT OF THE DISSERTATION

\title{
ATTENTIONAL PROCESSES IN ANXIETY: EXAMINING THREAT-RELATED ATTENTION BIAS AND ATTENTIONAL CONTROL IN ANXIOUS YOUTH
}

by

\author{
Raquel Melendez
}

Florida International University, 2019

Miami, Florida

Professor Jeremy W. Pettit, Major Professor

Attention bias modification treatment (ABMT) is a computer-administered intervention informed by theoretical models implicating the role of attentional processes in the etiology and maintenance of anxiety. Attention bias modification treatment presents an innovative, cost-effective approach to meeting demand for treatment of anxiety disorders; however data are limited regarding long-term outcomes and related predictors of ABMT treatment outcomes in youth. Therefore, the present study examined long-term outcomes of ABMT as a standalone or adjunctive treatment in 74 youth referred to an anxiety disorders clinic. Three groups of youth (ages 9 to 22) were identified and assessed approximately one to six years (average four years) following their most recent in-clinic assessment: 1) youth who completed only a pretreatment assessment (assessed only group; $n=12$ ); 2) youth who completed ABMT only (ABMT group; $n$ = 34); and 3) youth who completed ABMT followed by CBT (ABMT+CBT group; $n=28)$. Long-term follow-up (LTFU) consisted of parent- and child self-report questionnaires assessing anxiety symptoms and anxiety-related impairment; clinician-rated assessment of anxiety symptom severity; and structured diagnostic interview. Multiple pairwise binary logistic regressions indicated that at LTFU, the assessed only, ABMT, and ABMT+CBT groups were statistically indistinguishable with respect to diagnostic recovery status. Multiple pairwise analyses of covariance controlling for baseline variables and time elapsed since their most recent assessment yielded no significant between-groups differences regarding treatment targets. Finally, separate hierarchical regressions indicated that variables assessed at pretreatment assessment, including attentional control, attention bias variability, minority status, anxiety symptoms, and anxiety symptom severity were not predictive of outcomes at post-assessment or LTFU in 
the ABMT group. Overall, parent, youth, and clinician ratings indicated levels of anxiety and related impairment at LTFU that fell below recommended clinical severity. These outcomes provide a promising outlook on the use of ABMT as a least-restrictive intervention for anxiety. Unfortunately, findings on predictors of outcomes are not as clear. Future research is encouraged to expand on these findings by further examining efficacy and predictors of outcomes within the context of a controlled trial to best identify which youth may benefit from ABMT as a standalone or adjunctive treatment. 


\section{TABLE OF CONTENTS}

CHAPTER

PAGE

I. INTRODUCTION TO THE RESEARCH.

II. ATTENTIONAL CONTROL SCALE FOR CHILDREN: FACTOR STRUCTURE AND CONCURRENT VALIDITY AMONG CHILDREN AND ADOLESCENTS REFERRED FOR

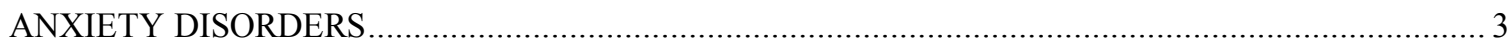

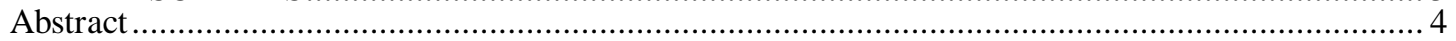

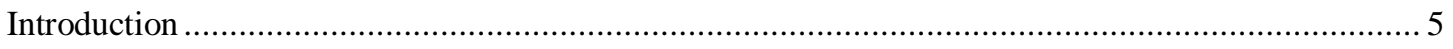

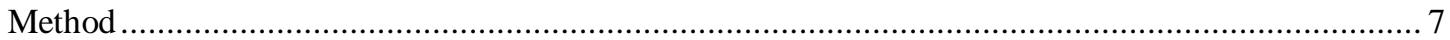

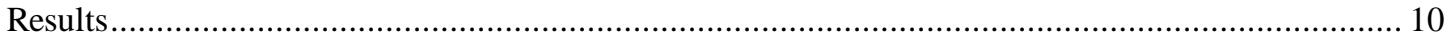

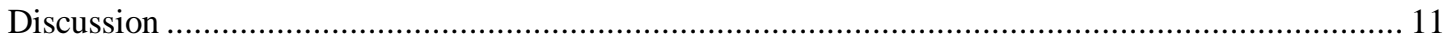

III. RELIABILITY OF THE DOT PROBE TASK TO MEASURE ATTENTIONAL THREAT BIAS

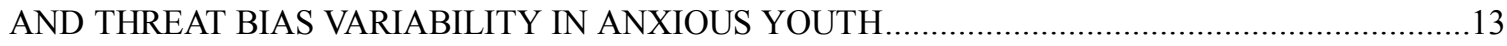

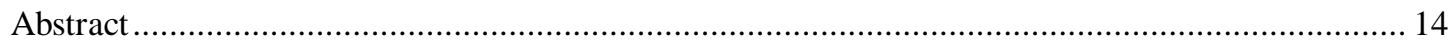

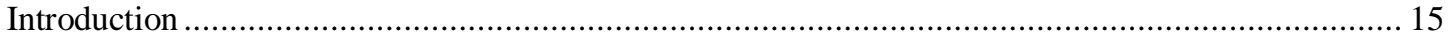

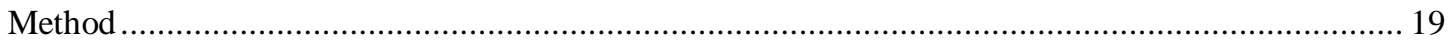

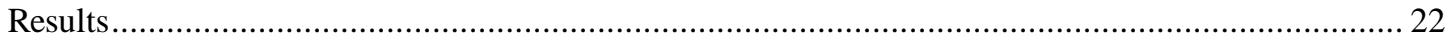

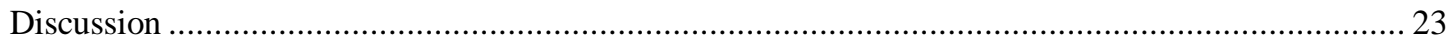

IV. LONG-TERM FOLLOW-UP OF ATTENTION BIAS MODIFICATION TREATMENT IN

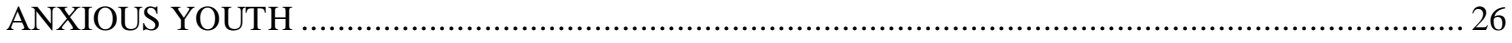

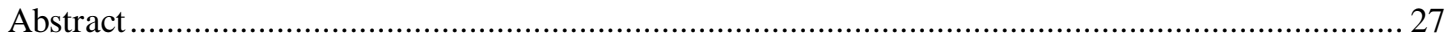

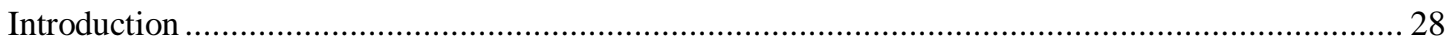

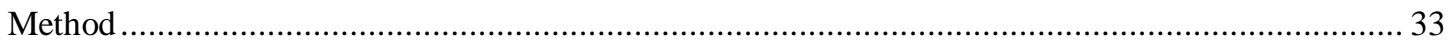

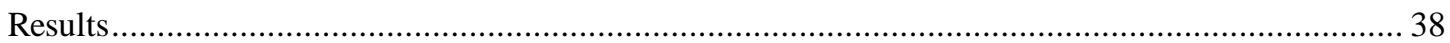

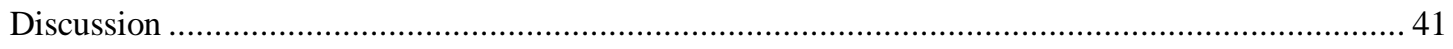

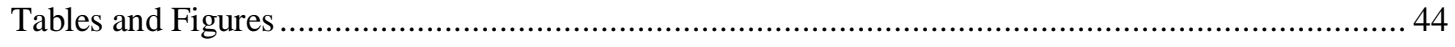

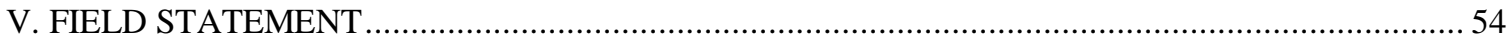

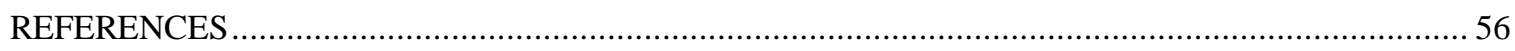

VITA 


\section{LIST OF TABLES}

TABLE

PAGE

Means of, standard deviations of, and correlations between measured variables ................................ 44

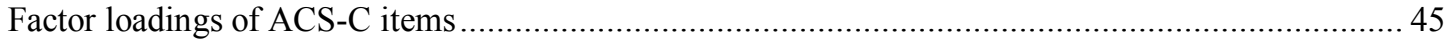

Means of, standard deviations of, and correlations between measured variables ................................ 46

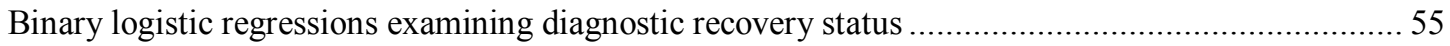

Comparison of outcomes on treatment targets at long-term follow-up between the assessed only and

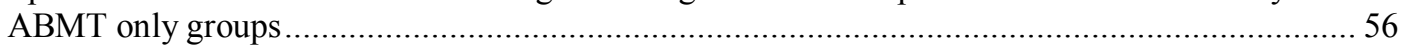

Comparison of outcomes on treatment targets at long-term follow-up between the ABMT only and

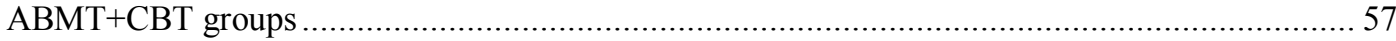

Comparison of outcomes on treatment targets at long-term follow-up between the ABMT+CBT and

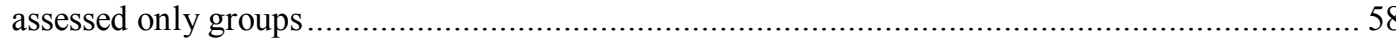

Descriptive statistics for measures collected at long-term follow-up ................................................ 59 


\section{INTRODUCTION TO THE RESEARCH}

My program of research focuses on the role of attentional processes in the etiology, maintenance, and treatment of anxiety in youth. The goals of my research include 1) the evaluation of tools used for measuring attentional control and threat-related attention bias and 2) examining how best to leverage these constructs to most effectively treat youth with anxiety disorders.

\section{Rationale for Research}

Anxiety disorders are highly prevalent in youth, result in substantial distress and impairment, and pose risk for development of subsequent or co-occurring disorders (Silverman \& Field, 2011). Shortage of trained practitioners and parental reluctance to use medication treatments for youth anxiety (Young et al., 2006) mean these approaches are unable to meet current demand (Bebbington et al., 2000; Bower \& Gilbody, 2005; Essau, Conradt, \& Petermann, 2002; Kazdin \& Blase, 2011; Keller et al., 1992; Lovell \& Richards, 2000; Vos et al., 2005; Weisz, 2000). Given the high prevalence of anxiety disorders among youth, the benefits of early intervention (Dadds et al., 1999), and the numerous obstacles impeding youth from receiving adequate treatment for anxiety, there is a need for least restrictive treatment options. Least restrictive treatments are defined by low cost and low personal investment on part of the patient and low burden of training and treatment delivery on part of the therapist (Breslin, Sobell, Sobell, Buchan, \& Cunningham, 1997). Attention bias modification treatment (ABMT) is a novel, least restrictive treatment targeting attentional constructs to ameliorate anxiety symptom severity that shows promise in anxious adult and youth populations.

\section{Presentation of Research Findings}

My dissertation examines the role of threat-related attention bias and attentional control in the etiology, maintenance, and treatment of anxiety disorders in youth. The dissertation portfolio consists of three separate manuscripts. Chapter II presents findings on the factor structure of the Attentional Control Scale for Children, a widely used self-report questionnaire assessing youth's abilities with respect to attentional shifting and attentional focusing. Given the high proportion of youth identifying as Hispanic/Latino in my data and the impact of racial and ethnic status on factor structure of other self-report questionnaires (Wren et al., 2007), I was particularly interested in 1) examining the factor structure of the English-language version for youth, and 2) examining how the questionnaire items were reflected across 
subscales in a sample comprised mostly of Hispanic/Latino youth. Chapter III examines the test-retest reliability of the dot probe task, the most commonly used computer-based measure for assessing threatrelated attention bias. Although threat-related attention bias has been implicated in research related to attention bias modification, data have indicated low reliability of original methods for calculating threatrelated attention bias using dot probe data (Brown et al., 2014). Thus, Chapter III examines multiple ways to use data from the dot probe task when calculating reliability of threat-related attention bias. Chapter IV examines the therapeutic extension of threat-related attention bias, attention bias modification treatment $(\mathrm{ABMT})$ as a standalone or adjunctive treatment to cognitive behavioral therapy (CBT). Although ABMT has been utilized alone or alongside CBT in adult and youth populations, no data exist on long-term maintenance of gains. Therefore, Chapter IV addresses the following questions: 1) how the assessed only, $\mathrm{ABMT}$, and $\mathrm{ABMT}+\mathrm{CBT}$ groups compare with respect to diagnostic recovery rates at LTFU; 2) how the assessed only, ABMT, and ABMT+CBT groups compare across treatment targets; and 3) what variables measured at pre-treatment intake assessment may predict ABMT outcomes at LTFU. I hypothesized that youth who received ABMT and CBT would demonstrate superior diagnostic recovery rates and report of anxiety symptoms and related impairment as compared to ABMT and assessed only youth. Finally, I hypothesized that minority status, anxiety symptoms and related impairment, and attentional control measured at pretreatment assessment intake may be associated with rates of anxiety symptoms, functional impairment, and attentional control at LTFU for youth who completed ABMT as a standalone treatment. 


\section{ATTENTIONAL CONTROL SCALE FOR CHILDREN: FACTOR STRUCTURE AND CONCURRENT VALIDITY AMONG CHILDREN AND ADOLESCENTS REFERRED FOR ANXIETY DISORDERS}

This manuscript has been published in Journal of Clinical Psychology, Volume 73, Issue 4, pages 489 to 499.

Melendez, R., Bechor, M., Rey, Y., Pettit, J. W., \& Silverman, W. K. (2017). Attentional control scale for children: Factor structure and concurrent validity among children and adolescents referred for anxiety disorders. Journal of Clinical Psychology, 73(4), 489-499.

Author's note: Work on this project was supported by National Institute of Mental Health grants R34 MH097931, UH2 MH101470, and R01 MH079943 to Jeremy W. Pettit and Wendy K. Silverman. The content is solely the responsibility of the authors and does not necessarily represent the official views of the National Institutes of Health 


\begin{abstract}
The Attentional Control Scale for Children (ACS-C; Muris, de Jong, \& Engelen, 2004) is a youth self rating scale of attentional control. Using a multisource assessment approach with 186 children and adolescents referred to an anxiety disorders specialty clinic, the present study examined the factor structure and concurrent validity of the ACS-C. Exploratory factor analysis yielded a two factor structure with internally consistent and moderately correlated subscales of Attentional Focusing and Attentional Shifting. Total ACS-C score and subscale scores demonstrated significant associations with child self ratings and parent ratings of child anxiety symptoms, child self ratings of depressive symptoms, and child diagnosis of ADHD. These findings support use of the ACS-C as a self rating scale of attentional control among referred children and adolescents. Future research is encouraged to examine retest reliability of the ACS-C and to evaluate whether its internal structure could be enhanced by removing or modifying items that performed poorly.
\end{abstract}

Keywords: Children; Adolescent; Anxiety; Attentional Control; Factor Analysis. 
Attentional Control Scale for Children: Factor Structure and Concurrent Validity among Children and Adolescents Referred for Anxiety Disorders

Introduction

Attentional processes play a prominent role in information processing models of anxiety and its disorders particularly with regard to development, maintenance, and treatment (Field, Hadwin, \& Lester, 2011). One attentional process that is garnering growing interest is attentional control. Attentional control (AC) refers to the ability to voluntarily and strategically focus, sustain, and shift one's attention (Derryberry \& Reed, 2002). High levels of AC enable children and adolescents (henceforth referred to as "youth") to modulate their emotional experiences by strategically focusing attention on and shifting attention away from stimuli (Puliafico \& Kendall, 2006). Low levels of AC hinder youths' ability to adaptively engage with negatively valenced and threatening stimuli, thereby contributing to the development and maintenance of anxiety and its disorders (Lonigan, Vasey, Phillips, \& Hazen, 2004; Muris \& Ollendick, 2005; Susa, Pitica, Benga, \& Miclea, 2012). Low levels of AC also have been implicated in the development and maintenance of disorders that frequently co-occur with anxiety in youth, including depression and attention-deficit hyperactivity disorder (ADHD; Bechor, et al., unpublished manuscript; Nigg, 2006).

Attentional control has been most commonly assessed in youth using the Attentional Control Scale for Children (ACS-C; Muris, de Jong, \& Engelen, 2004) a 20 item self rating scale. The ACS-C is a downscaled adaptation of the adult Attentional Control Scale (Derryberry \& Reed, 2002). Research supports the ACS-C's convergent validity and concurrent validity among nonreferred youth. With regards to convergent validity, significant associations have been found between ACS-C scores and scores on performance based tests of selective attention, attentional switching, and sustained attention (Muris, Mayer, Lint, \& Hofman, 2008). With regards to concurrent validity, significant cross-sectional associations have been reported between ACS-C scores and self and parent ratings on measures of youth anxiety symptom severity (Muris et al., 2004; Muris, et al., 2008; Muris, Meesters, \& Rompelberg, 2007), youth depressive symptom severity (Muris et al., 2008; Muris et al., 2006), and youth ADHD symptom severity (Muris et al., 2008; Muris et al., 2006). 
We are not aware of any published study on the factor structure of the ACS-C. One study (Verstraeten et al., 2010) evaluated the factor structure of a Dutch language version of the Attentional Control Scale (adult version) among 280 nonreferred youths ( $M_{\text {age }}=12.28$ years, $S D=2.46$ ) sampled from two Belgian schools. Among these 280 youths, support was obtained for a two-factor model with factors representing Attentional Focusing and Attentional Shifting (Verstraeten et al., 2010). We also are not aware of any published study that has reported on the psychometric properties or validity of the ACS-C in a clinic referred sample, including youth referred for anxiety and its disorders.

Given the theorized role of AC in development and maintenance of anxiety (Derryberry \& Reed, 2002), as well as growing interest in targeting AC in interventions for youth with anxiety (Heeren, de Raedt, Koster, \& Philippot, 2013; Wass, Porayska-Pomsta, \& Johnson, 2011), there is a need to establish whether the ACS-C is a psychometrically sound measure of AC for use among referred youth. The present study sought to address this need by examining the factor structure and concurrent validity of the ACS-C among youth referred for anxiety. Exploratory factor analysis (EFA) was used because this was the first study to evaluate the factor structure of the ACS-C. Concurrent validity was evaluated via associations between youth self ratings on the ACS-C and parent ratings and youth self ratings on a measure of anxiety symptoms. As in past studies among nonreferred youth (Muris et al., 2008; Muris et al., 2006), concurrent validity also was evaluated via associations between youth self ratings on the ACS and youth self ratings on a measure of depressive symptoms and youth diagnosis of co-occurring ADHD. Given low to modest agreement across informant sources in the youth anxiety literature (Silverman \& Ollendick, 2005), a multisource assessment approach was used to evaluate concurrent validity. Consistent findings across informant sources would enhance confidence in the robustness of findings.

Based on theory and past empirical research in nonreferred samples, we expected scores on the ACS-C would be significantly and negatively associated with scores on measures of anxiety symptoms and depressive symptoms. We also expected youth who met diagnostic criteria for ADHD would display significantly lower scores on the ACS-C than youth who did not meet criteria for ADHD. 


\title{
Material and Methods
}

\section{Participants}

Participants were 186 youths ages 6 to 17 years $\left(58 \%\right.$ boys; $\left.M_{a g e}=9.66 ; S D_{a g e}=2.48\right)$ who were referred to an anxiety disorders specialty clinic. Approximately $83 \%$ of the sample identified as Hispanic/Latino, 12\% identified as European American, and 5\% identified as Other race/ethnicity. Annual household income was reported by parents and was as follows: $11 \%$ reported below $\$ 21,000,13 \%$ reported between $\$ 21,000$ and $\$ 40,000,20 \%$ reported between $\$ 41,000$ and $\$ 60,000,16 \%$ reported between $\$ 61,000$ and $\$ 80,000$, and $40 \%$ reported over $\$ 81,000$. The most common primary diagnoses were generalized anxiety disorder (29.0\%), social anxiety disorder (21.0\%), separation anxiety disorder (18.3\%), and specific phobia (11.8\%). Twenty percent of the sample met criteria for a diagnosis of ADHD (primary, secondary, or tertiary).

\section{Measures}

\section{Diagnostic measure.}

\author{
Anxiety Disorders Interview Schedule- Child and Parent Version - IV (ADIS-C/P-IV; Silverman \\ \& Albano, 1996). The ADIS-C/P contains 0- to 8-point clinician severity rating (CSR) scales to assess \\ the severity and interference of diagnoses. The ADIS-C/P has yielded good to excellent reliability \\ estimates for specific anxiety diagnoses and symptoms as well as excellent retest reliability estimates \\ over two weeks (Silverman, Kurtines, Jaccard, \& Pina, 2009). Convergent validity has been \\ demonstrated via significant associations with youths' self ratings on anxiety (Silverman, Saavedra, \& \\ Pina, 2001; Wood, Piacentini, Bergman, McCracken, \& Barrios, 2002). Based on youth and parent \\ responses to the ADIS, dichotomously scored variables representing presence (1) or absence (0) of \\ specific youth anxiety disorder diagnoses and youth ADHD diagnosis were created and used in \\ analyses.
}




\section{Measures completed by youth.}

Attentional Control Scale for Children (ACS-C; Muris et al., 2004). The ACS-C is a 20-item youth self rating scale that assesses abilities to focus and shift attention. Responses are scored on a 4point Likert scale that ranges from 1 (Almost Never) to 4 (Always). After reverse coding, higher scores indicate better AC. Cronbach's alpha for this sample was .74.

Revised Children's Manifest Anxiety Scale - Child Version (RCMAS-C; Reynolds \& Richmond, 1978). The RCMAS-C is a $37-$ item youth self rating scale that assesses anxiety symptoms. Each item is rated either yes or no, scored 1 or 0 . A Total Anxiety score is computed by summing ratings on 28 items. The remaining nine items comprise a lie subscale. The RCMAS-C has demonstrated high retest reliability (.98) over a three week period (Pela \& Reynolds, 1982). Convergent validity has been demonstrated via significant correlations with trait anxiety and fear (Ollendick, 1983). Cronbach's alpha for this sample was .88 .

Children's Depression Inventory (CDI; Kovacs, 1985). The CDI is a 27-item youth self rating scale that assesses depressive symptoms. Each item contains three response options and youths are instructed to select the option that best describes them during the previous two weeks. Thirteen items are reverse scored and summed with the remaining items to obtain an overall score. Convergent validity has been demonstrated via significant correlations with independent evaluator rated measures of depressive symptoms and youth self ratings on other measures of depressive symptoms (Brooks \& Kutcher, 2001; Klein, Dougherty, \& Olino, 2005; Shain, Naylor, \& Alessi, 1990). Cronbach's alpha for this sample was .88 .

\section{Measure completed by parents.}

\section{Revised Children's Manifest Anxiety Scale - Parent Version (RCMAS-P; Reynolds \&}

Richmond, 1978). In the RCMAS-P, the wording of RCMAS items was changed from I to my child, as done in past research (e.g., Kendall, 1994; Silverman et al., 1999, 2009). Cronbach's alpha for this sample was .85 . 


\section{Procedures}

The present study was approved by the Institutional Review Board. Parents provided informed consent and youth provided assent. Assessments were conducted by graduate students who had been thoroughly trained in the study's procedures. Upon arrival at the clinic, youth participants and their parents (usually mothers) were administered the respective versions of ADIS-C/P-IV and the RCMAS-C/P. Youth also completed the ACS-C and CDI. All measures were completed at a pretreatment intake assessment.

\section{Statistical Analysis}

Statistical analyses were performed using the SPSS statistical software program version 20. Missing data was minimal, not exceeding $4.8 \%$ of cases for any variable. Missing data was assessed by computing a dummy variable representing the presence or absence of missing data for each variable. This dummy variable was then correlated with all other variables including demographic variables. No significant correlations were observed, indicating no evidence of bias due to missing data. Missing data was accommodated using maximum likelihood multiple imputation averaged across ten iterations (Graham, 2009).

The data were examined for evidence of non-normality. Evidence of skew was present on the CDI. Evidence of kurtosis was present on the CDI and RCMAS-C. Because of its ability to accommodate nonnormality of the data, principal axis factoring was used to examine the factor structure of the ACS-C (Fabrigar, Wegener, MacCallum, \& Strahan, 1999). A scree plot was evaluated such that the primary bend in the plot was used to determine the number of factors for extraction. Oblique (Direct Oblimin) rotations were used because we expected factors to be intercorrelated. Items with loadings of .32 or greater were considered indicators of a factor (Costello \& Osborne, 2005).

Bivariate correlations were used to evaluate associations between scores on the ACS-C and other measured variables. Two-tailed Pearson correlations were used for analyses involving pairs of continuous variables and point biserial correlations were used for analyses involving dichotomous variables. 


\section{Results}

Means, standard deviations, and correlations between measured variables are presented in Table 1. Scores on the ACS-C did not significantly vary according to youth age, sex, race, ethnicity, or anxiety diagnosis.

\section{Exploratory factor analysis}

Evaluation of the scree plot suggested the extraction of three factors. The three factor solution accounted for $27.79 \%$ of the variance in ACS-C items. Only three items loaded on the third factor and internal consistency of the third factor was inadequate $(\alpha=.33)$. Because of the inadequate internal consistency of the third factor, which is common in subscales with a low number of items (Floyd \& Widaman, 1995), a two factor solution was evaluated.

The two factor solution accounted for $22.97 \%$ of the variance in ACS-C items. Item loadings for the two-factor solution are presented in Table 2. Nine items had loadings of .32 or higher on the first factor, the majority describing ability to focus attention. The first factor thus was labeled "Attentional Focusing." Responses to these nine items were summed to create total scores on an Attentional Focusing subscale $(\alpha=$ 0.77). Six items, all describing ability to shift attention, had loadings of .32 or higher on the second factor. Therefore, the second factor was labeled "Attentional Shifting." Responses to these six items were summed to create total scores on an Attentional Shifting subscale $(\alpha=0.64)$. Items four, five, nine, 15 , and 16 did not have loadings of 0.32 or higher on either factor.

\section{Concurrent validity}

Bivariate correlations were used to evaluate concurrent associations between scores on the total ACS-C, the two ACS-C subscales, measures of youth anxiety symptoms, the measure of youth depressive symptoms, and youth diagnosis of ADHD (see Table 1). The correlation between Attentional Focusing and Attentional Shifting was significant and positive; the strength of the correlation was moderate $(r=0.42)$. As hypothesized, total scores on the ACS-C were significantly and negatively correlated with scores on measures of youth self rated and parent rated anxiety symptom severity and scores on the measure of youth 
depressive symptom severity. Scores on the total ACS-C also were significantly associated with a diagnosis of ADHD, such that youth who met diagnostic criteria for ADHD displayed significantly lower levels of AC than youth who did not meet criteria for ADHD.

Scores on the Attentional Focusing subscale and the Attentional Shifting subscale were significantly and negatively correlated with scores on measures of youth self rated and parent rated anxiety symptom severity, scores on the measure of youth depressive symptom severity, and a youth diagnosis of ADHD.

\section{Discussion}

Findings from this exploratory factor analysis of the ACS-C among referred youth provide evidence of two moderately correlated and internally consistent factors: Attentional Focusing and Attentional Shifting. Concurrent validity was supported via significant cross-sectional correlations with youth and parent ratings on anxiety symptoms, youth self ratings on depressive symptoms, and a youth diagnosis of ADHD.

The two factor structure of the ACS-C found in this sample of referred youth aligns with findings of a two factor structure of the adult Attentional Control Scale (Judah et al., 2014; Ólafsson et al., 2011). Thus, converging evidence from youth samples and adult samples indicates the construct of AC consists of two related but distinguishable factors. One factor, Attentional Focusing, describes the ability to maintain attention on a stimulus. A second factor, Attentional Shifting, describes the ability to shift attention from one stimulus to another. Although the majority of items loaded on either the Attentional Focusing factor or the Attentional Shifting factor, five items did not load on either factor. These same five items also did not load on either factor of the adult version of Attentional Control Scale in a sample of nonreferred adults (Judah, et al., 2014). These items do not appear to measure either attentional focusing or attentional shifting in youths or adults. If replicated in other youth samples, removal of these items from the ACS-C may lead to improved internal structure. 
Three items originally purported to measure attentional shifting on the adult Attentional Control Scale (Derryberry \& Reed, 2002) loaded on the Attentional Focusing factor of the ACS-C in this sample (items 11, 12, and 20). Two of these same items (items 12 and 20) also loaded on an Attentional Focusing factor in studies on the factor structure of the adult Attentional Control Scale (Judah et al., 2014; Ólafsson et al., 2011). Thus, a growing body of evidence indicates items 12 and 20, and possibly item 11, should be considered measures of attentional focusing rather than attentional shifting. Of note, the wording of these items appears to align as closely with focusing as shifting (e.g., "When I have to start a new task, it takes me a while to get really involved in it"; "When the teacher explains something, I find it difficult to understand and write it down at the same time").

The findings of this study should be interpreted in light of its strengths and limitations. Strengths include the use of a clinic referred sample of youth, semistructured interviews to establish diagnoses, and a multisource assessment approach for youth anxiety symptoms. Limitations include our inability to examine retest reliability of the ACS-C and evaluate convergent validity of the ACS-C via associations with other self report or performance based measures of AC. Further, although ACS-C scores were not significantly correlated with participant age in this study, it would be of interest to examine the ACS-C from a developmental perspective. For example, when do focusing and shifting emerge as separate facets of AC, and do their respective associations with anxiety symptom severity differ across developmental levels? Given sample size constraints and a preponderance of participants in late childhood-early adolescence, we were not in a position to evaluate the factor structure and concurrent validity of the ACS-C across development.

In spite of these limitations, the present study provides the first empirical data on the factor structure of the ACS-C and provides evidence of concurrent validity of the ACS-C among referred youth. These findings support use of the ACS-C as a self rating scale of attentional focusing and attentional shifting among referred youth. Future research is encouraged to examine retest reliability and convergent and discriminant validity of the measure and to evaluate whether the internal structure of the measure could be enhanced by removing items that performed poorly. 


\section{RELIABILITY OF THE DOT PROBE TASK TO MEASURE ATTENTIONAL THREAT BIAS AND THREAT BIAS VARIABILITY IN ANXIOUS YOUTH}

This manuscript was submitted to the Journal of Anxiety Disorders, and thus adheres to its use of APA $6^{\text {th }}$

Edition formatting guidelines.

Melendez, R., Bechor, M., Buitron, V., Rey, Y., Pettit, J. W., \& Silverman, W. K. (under review).

Reliability of the dot probe task to measure attentional threat bias and threat bias variability in anxious youth. 


\begin{abstract}
Split-half reliability and test-retest reliability of the dot probe task used to measure attentional threat bias has not been examined in clinic-referred youth. The present study examined the split-half and test-retest reliability of attentional threat bias as well as the test-retest reliability of attention bias variability, a recently developed index measuring intrasession fluctuations in attentional threat bias. The sampled 126 youths (ages 6 to 17 years) completed the dot probe task at two waves, 8 days apart on average. Attentional threat bias and attention bias variability scores were computed at each wave. Split-half reliability and testretest reliability of the attentional threat bias index were nonsignificant and low. Test-retest reliability of the attention bias variability index was also low but statistically significant. Given the widespread use of dot probe tasks, investigators are encouraged to explore task modifications to increase reliability and evaluate alternative methods of measuring attention to threat.
\end{abstract}

Keywords: Children; Adolescent; Anxiety; Attentional Bias; Attentional Bias Variability; Dot Probe 
Reliability of Attentional Threat Indices on a Dot Probe Task in Children and Adolescents with Anxiety Disorders

Introduction

Information processing models of anxiety link individuals' biases to attend to threatening stimuli with anxiety disorders and anxiety symptom severity (Mathews \& MacLeod, 1994). Compelling support for an association between attentional threat bias and anxiety comes from meta-analytic reviews of studies with mixed age samples (Bar-Haim, Lamy, Pergamin, Bakermans-Kranenburg, \& Van, 2007), including child and adolescent samples (Dudeney, Sharpe, \& Hunt, 2015).

The most widely used measure of attentional threat bias is a variation of the visual probe-detection task, also referred to as the dot probe task (MacLeod, Mathews, \& Tata, 1986). In the dot probe task used to measure attentional threat bias, two stimuli are presented simultaneously (i.e., one neutral and one threatening), followed by a probe appearing in the place of one of the stimuli. Participants are instructed to indicate the location of the probe as quickly as possible via a behavioral response, most often a computer mouse click. Researchers then calculate an attentional bias index by subtracting each participant's average response times for when the probe replaces the threatening stimulus from average response times for when the probe replaces the neutral stimulus. A positive score is considered an indicator of an attentional threat bias.

Although the attentional threat bias index measured by the dot probe task has been widely used for over a decade in anxious and non-anxious samples of youths and adults (Bar-Haim et al., 2007), recent research findings raise concerns about its internal consistency reliability and test-retest reliability (Brown et al., 2014; Schmukle, 2005; Staugaard, 2009; Waechter, Nelson, Wright, Hyatt, \& Oakman, 2013; Waechter \& Stolz, 2015) . Establishing a psychometrically sound task for measuring attentional threat bias indices is crucial to advancing theory of and understanding of attentional threat bias in youth anxiety. That is, tests of theory driven hypotheses on attentional threat bias in youth anxiety require reliable measurement of attentional threat bias. These include tests of attentional threat bias in the etiology and maintenance of youth anxiety (Lonigan \& Vasey, 2009; Roy, Dennis, \& Warner, 2015), as well as tests of attentional threat bias as a predictor, moderator, or mediator of child and adolescent anxiety intervention outcomes (Amir, 
Taylor, \& Donohue, 2011; Legerstee et al., 2009; M. Price, Tone, \& Anderson, 2011; Waters, Mogg, \& Bradley, 2012). In the absence of a psychometrically sound measure, theoretical advancement will be stalled. In the following sections, we briefly review recent research findings on the internal consistency reliability and test-retest reliability of attentional threat bias measured using the dot probe task.

\section{Internal Consistency Reliability of the Attentional Threat Bias Index}

Previous studies examining internal consistency reliability of attentional threat indices generated by the dot probe task have commonly used split-half reliability and Cronbach's alpha. In split-half reliability, trial-level difference scores from the dot probe are randomly split into two halves, and the total bias scores from each half are correlated. In Cronbach's alpha, the data are split in all possible ways, and the correlations of all splits are averaged. Estimates of internal consistency reliability have been uniformly low in nonreferred samples. Split-half reliability estimates have ranged from $r=.12, p>.05$ to $r=.33, p<$ .05 in nonreferred children (Brown et al., 2014), $r s=-.29$ to $.37, p s>.05$ in undergraduate students (Schmukle, 2005; Staugaard, 2009), and $r s=-.33$ to .32, ps > .05 in nonreferred adults (Cooper et al., 2011). Internal consistency reliability estimates also have been low in undergraduate students selected on the basis of either low or high scores on self-rated anxiety scales, with split-half reliability ranging from $r \mathrm{~s}$ $=.09$ to $.29, p \mathrm{~s}>.05$ (Waechter \& Stolz, 2015) and Cronbach's alpha ranging from $\alpha s=-.55$ to $.38, p s>$ .05 (Waechter et al., 2013).

Split-half reliability was $r=.45, p<.001$ in adults selected on the basis of exposure to war-related stress (Bar-Haim, 2010). Enock et al. (2014) reported split-half reliability on each of six administration waves of the dot probe task in adults seeking treatment for social anxiety symptoms. Split-half reliability generally increased across successive administrations of the task, from $r \mathrm{~s}=.00$ to $-.05, p \mathrm{~s}>.05$ at the first administration to $r \mathrm{~s}=.31$ to $.53, p \mathrm{~s}>.05$ at the sixth administration.

\section{Test-Retest Reliability of the Attentional Threat Bias Index}

Studies have also reported on the test-retest reliability of scores on the attentional threat bias index in nonreferred and referred adults and youth by correlating scores on two administrations of the task 
separated by intervals of approximately one to two weeks. Test-retest reliability has been uniformly low in studies that administered dot probe tasks at two sessions spanning one to two week intervals, with testretest of $r=-.06, p>.05$ in nonreferred children (Brown et al., 2014) and test-retest ranging from $r s=-.18$ to $.26, p \mathrm{~s}>.05$ in nonreferred undergraduate students (Schmukle, 2005; Staugaard, 2009).

Test-retest reliability has been low to moderate in two studies that administered dot probe tasks at four to twelve sessions spanning as many as 14 weeks (Enock et al., 2014; Price et al., 2015). Among adults seeking treatment for social anxiety symptoms, test-retest reliability generally increased across six successive administrations, from $r \mathrm{~s}=-.25$ to $.05, p \mathrm{~s}>.05$ across the first two administrations to $r s=.61$ to $.63, p s<.001$ across the final two administrations (Enock et al., 2014).

Price et al. (2015) examined test-retest reliability of the attentional threat bias index in three samples: a sample of nonreferred children and adolescents who completed the dot probe task five times over a 14-week period and two samples of adults who met criteria for social anxiety disorder and completed the task twice weekly for 4 and 6 weeks, respectively. Intraclass correlation coefficients (ICCs) across five administrations in children and adolescents ranged from -.23, $p>.05$ to $.55, p<.05$ depending which administrations of the task and which trials on the task were used in analyses. The highest test-retest reliability was obtained when ICCs were averaged across all successive administrations of the task and all trials on the task were used (ICC $=.55, p<.05)$. Among adults, ICCs across 8 or 12 administrations ranged from $-1.50, p>.05$ to $.65, p<.05$ depending on which administrations of the task which trials on the task were used. Highest test-retest reliability was obtained when ICCs were averaged across all successive administrations of the task and only probe-on-bottom trials were used (ICCs $=.55, p<.05$ and $.49, p<.05$, respectively).

\section{Test-Retest Reliability of the Attentional Threat Bias Variability Index}

Because of the above summarized research showing low to moderate internal consistency reliability and test-retest reliability of the attentional threat bias index, researchers have suggested alternative ways of calculating attentional threat bias (Price et al., 2015; Van Bockstaele et al., 2014; Waechter \& Stolz, 2015). Researchers have recently proposed attentional threat bias variability (ABV) 
scores on the dot probe task as possibly more reliable than the attentional threat bias index (Iacoviello et al., 2014; Naim et al., 2015; Price et al., 2015). The ABV indices quantify within-subject intrasession variability on the dot probe task, potentially providing more reliable measures across sessions than the attentional threat bias index (Price et al., 2015). The ABV indices have been calculated using two approaches.

In the first approach, an ABV index is calculated by partitioning threat-neutral trials into multiple bins (i.e., groups) of approximately 20 trials each and then calculating the attentional threat bias index for each bin. The standard deviation of the attentional threat bias index is then calculated and divided by participants' mean reaction times across all threat-neutral trials (Price et al., 2015).

In the second approach, an ABV index is calculated using a moving average algorithm. Mean reaction times are calculated for successive blocks of ten threat trials and ten neutral trials. The attentional threat bias index is calculated for each block by subtracting the first neutral block mean reaction time from the first threat block mean reaction time, the second neutral block mean reaction time from the second threat block mean reaction time, and so on. The standard deviation of the successive attentional threat bias scores is then calculated and divided by the participant's overall mean reaction times across all trials (Naim et al., 2015).

We are aware of two studies that reported on the test-retest reliability of the ABV index (Naim et al., 2015; Price et al., 2015). In Price et al. (2015), scores on the ABV index across six administrations of the dot probe task yielded averaged ICCs ranging from .47 to $.68, p s<.05$ in nonreferred children and adolescents. The ABV index across 8 to 12 administrations yielded averaged ICCs ranging from $.54, p<$ .05 to $.96, p<.05$ in socially anxious adults (R. B. Price et al., 2015). In another study using nonreferred undergraduates $(n=70)$ and veterans with PTSD $(n=37)$, Naim et al. (2015) examined the test-retest reliability of the ABV index across two administrations of the dot probe task over a one week interval, yielding test-retest of $r=.29, p<.05$ for the undergraduate sample and $r=.40, p<.05$ for the PTSD sample. 


\section{Present Study}

No study has reported on the internal consistency reliability and test-retest reliability of the attentional threat bias index or ABV index in clinic referred children and adolescents. To address this gap in the research, the present study examined the split-half reliability and test-retest reliability of scores on the attentional threat bias index and test-retest reliability of scores on the ABV index in clinic referred children and adolescents with anxiety disorders.

\section{Method}

\section{Participants}

Participants were 126 children and adolescents ages 6 to 17 years ( $48 \%$ boys; $M_{\text {age }}=9.60 ; S D_{\text {age }}=$ 2.59) referred to an anxiety disorders specialty clinic. Participants were Hispanic/Latino (86\%), European American (10\%), African-American (1\%), or Other race/ethnicity (3\%). Annual household income was as follows: $10 \%$ below $\$ 21,000 ; 22 \%$ between $\$ 21,000$ and $\$ 40,000 ; 19 \%$ between $\$ 41,000$ and $\$ 60,000 ; 15 \%$ between $\$ 61,000$ and $\$ 80,000$; and $34 \%$ over $\$ 81,000$. The remaining $2 \%$ declined to report income. The most common primary diagnoses were generalized anxiety disorder (26.1\%), separation anxiety disorder (18.5\%), social anxiety disorder (18.5\%), and specific phobia (13.4\%). Two-tailed Pearson correlations showed that scores on the attentional threat bias index and the ABV index did not significantly differ as a function of participants' sex or income. One way analyses of variance showed that scores on the indices did not significantly differ as a function of participants' race/ethnicity or primary diagnosis.

\section{Measures}

\section{Anxiety Disorders Interview Schedule- Child and Parent Version - IV (ADIS-C/P-IV;}

Silverman \& Albano, 1996). The ADIS-C/P is a semistructured interview schedule that has yielded good to excellent reliability estimates for anxiety diagnoses and symptoms (kappa $=.57-1.0)$ as well as excellent retest reliability estimates over two weeks ( $r=.80$ to .92 ; Lyneham et al., 2007; Silverman, Kurtines, Jaccard, \& Pina, 2009; Silverman, Saavedra, \& Pina, 2001). Convergent validity has been 
demonstrated via significant associations with child and adolescent anxiety self report (Silverman et al., 2001; Wood, Piacentini, Bergman, McCracken, \& Barrios, 2002).

Dot probe task. Participants completed the dot probe task using facial stimuli, modified for use with children and adolescents (TAU-NIMH ABMT initiative; http://tau.ac.il/ yair1/ABMT. html). Participants were presented with 120 trials. Each trial began with a centered fixation cross presented for 500 milliseconds (ms) followed by a pair of vertically oriented faces presented for $500 \mathrm{~ms}$. Pictorial stimuli included images of the same actor with either a neutral or threatening expression. Each trial included one of three of the following possible combinations: neutral-threat, threat-neutral, or neutral-neutral. A probe ("“<” or ">") appeared behind the top or bottom image and remained onscreen until participants indicated the orientation of the probe by clicking the left (" $<$ ") or right (">") mouse button using their dominant hand. The subsequent trial began immediately following participant response. Threat-face location, probe location, probe type, and actor were fully counterbalanced in presentation.

Attentional threat bias index. The attentional threat bias index was calculated by subtracting reaction times to congruent trials (i.e., probe located behind threatening stimulus) from reaction times to incongruent trials (i.e., probe located behind neutral stimulus), such that positive difference scores indicated a bias towards threat and negative difference scores indicated a bias away from threat. As in past studies (Bar-Haim et al., 2011), inaccurate responses, trials with response latencies $<150 \mathrm{~ms}$ and $>1200 \mathrm{~ms}$, and trials with response latencies \pm 2.5 SDs from the participant's mean were excluded. Responses on neutralneutral trials and trials with inaccurate responses were excluded.

Attention bias variability index. An ABV index was calculated using two approaches. The first approach (ABV; Iacoviello et al., 2014; Price et al., 2015) involved partitioning threat-neutral trials into six bins of 20 trials each and then calculating the attentional threat bias index for each bin. The standard deviation of the six attentional bias indices was then calculated and divided by participants' mean reaction times across all threat-neutral trials. Responses on neutral-neutral trials and trials with inaccurate responses were excluded. 
The second approach involved using a moving average algorithm (ABV-MA; Naim et al., 2015). Trial-level mean reaction times were calculated for successive blocks of ten threat trials and ten neutral trials. Attentional threat bias scores were calculated successively for each block by subtracting the first neutral block average from the first threat block average, and so on. Finally, the standard deviation of these successive threat bias scores was calculated and divided by participants' overall mean reaction times.

Attentional threat bias and $\mathrm{ABV}$ scores also were calculated using only trials with the probe presented on the bottom and only trials with the probe presented on the top (Price et al., 2015). Conclusions did not differ based on location of the probe; for ease of presentation, we report findings when all trials were included.

\section{Procedures}

The study was approved by the university's Institutional Review Board. Parents provided written informed consent and children and adolescents provided written informed assent. Dot probe administrations were conducted by graduate research assistants trained in ABMT by a licensed clinician. The dot probe task was completed at two separate pretreatment baseline assessments scheduled on average 8 days apart (range $=1-21$ days; $S D=3.58)$. Interval length was not significantly associated with any score and statistically controlling for interval length did not affect study conclusions; we thus report findings without controlling for interval length.

\section{Statistical Analysis}

Statistical analyses were performed using the SPSS statistical software program version 20. Missing data did not exceed $16.5 \%$ of cases for any variable. Missing data bias was assessed by computing a dummy variable representing the presence or absence of missing data for each variable. The dummy variable was then correlated with other variables including demographic variables. No significant correlations were observed, indicating no evidence of bias. Missing data were accommodated using maximum likelihood multiple imputation averaged across ten iterations (Graham, 2009). 
To calculate split-half reliability of the attention threat bias index, reaction times to randomly selected individual congruent trials were subtracted from reaction times to randomly selected incongruent trials. The resulting trial-level difference scores were split into two halves, and the total bias scores from each half were correlated. Two-tailed Pearson correlations were used to examine test-retest reliability of the attentional threat bias index and the two ABV indices collected during the two assessment waves.

\section{Results}

Means, standard deviations, and correlations between the attentional threat bias index and the $\mathrm{ABV}$ indices at both assessment waves are presented in Table 3. On average, participants displayed low negative scores on the attentional threat bias index at both assessment waves, indicating negligible bias away from threat. Attentional threat bias index scores and ABV scores were significantly and negatively correlated $(r=-.20, p=.03)$ at the first assessment wave, indicating lower mean levels of attention to threat were associated with higher intra-session variability in attentional threat bias. The correlation between attentional threat bias index scores and ABV scores was not statistically significant at the second assessment wave $(r=.06, p=.52)$. The correlation between attentional threat bias index scores and ABVMA scores was not statistically significant at either wave $(r=.04, p=.69 ; r=-.06, p=.49)$. The ABV and ABV-MA scores were significantly positively correlated at the second wave $(r=.48, p<.001)$ but not the first. The ABV scores $(r=-.29, p=.001)$ and ABV-MA scores $(r=-.28, p=.002)$ were significantly and negatively correlated with age at the first wave such that the younger children displayed higher intrasession variability in attentional threat bias than the older children, but not at the second wave.

\section{Reliability}

Split-half reliability of the attentional threat bias index was nonsignificant and low at the first assessment wave $(r=.004, p=.96)$ and statistically significant but still low at the second assessment wave $(r=.18, p=.04)$. Test-retest reliability of the attentional threat bias index was nonsignificant and negative $(r=-.13, p=.15)$. Test-retest reliability of ABV scores was statistically significant but low $(r=.21, p=$ $.01)$. Test-retest reliability of ABV-MA scores was not statistically significant $(r=.12, p=.18)$. 


\section{Discussion}

The present study provides further evidence of low reliability of the attentional threat bias index measured using the dot probe task, and extends findings of low reliability to a sample of clinic referred children and adolescents with anxiety disorders. Internal consistency reliability of the attentional threat bias index, as estimated using split-half reliability, was low at two separate assessment waves, and test-retest reliability across the two waves was nonsignificant and negative. Test-retest reliability of the ABV index, a recently proposed alternative to the attentional threat bias index, was statistically significant but still low. Test-retest reliability of the ABV-MA index was not statistically significant.

The split-half reliability of the attentional threat bias index was higher at the second administration than the first administration. Increases in split-half reliability and test-retest reliability have been reported across repeated administrations of the dot probe task (Enock et al., 2014; Price et al., 2015), suggesting that repeated practice with the task may lead to more reliable patterns of responding. It is possible that additional administrations of the dot probe task might have resulted in superior reliability estimates in this sample of clinic referred children and adolescents with anxiety disorders. The use of only two assessment waves precluded our ability to address this possibility.

These findings have troubling implications for the advancement of theory on attentional threat bias in anxiety. Namely, low internal consistency reliability and low test-retest reliability of the dot probe for attentional threat impede our ability to test theory driven hypotheses about the role of attentional threat bias in the etiology and maintenance of anxiety in youth, as well as the role of attentional threat bias as a predictor, moderator, or mediator of treatment outcomes. In the absence of a psychometrically sound measure, the field cannot move forward in this important area of theoretical and empirical inquiry. These findings also highlight the need for caution in using these attentional threat bias indices to select and/or assign anxious children and adolescents to certain treatments.

In light of the growing evidence of poor psychometrics of the attentional threat bias index, as well as the present findings of low test-retest reliability of the ABV index, shifts of the measurement of attentional threat bias may be necessary to move the field forward. Recent departures from the 
conceptualization of attentional threat bias as a static construct include development of a trial-level bias score (TL-BS) to account for variability in expression of attentional bias over time using data from the dot probe task (Zvielli, Bernstein, \& Koster, 2014). The TL-BS method calculates multiple, sequential attentional threat bias scores using difference scores from temporally contiguous pairs of individual incongruent and congruent trials. Initial findings supported the ability of TL-BS scores to discriminate between spider-phobic adults and healthy controls. We are not aware of studies reporting on reliability of the TL-BS index in anxious samples, although moderate split-half reliability estimates $(r \mathrm{~s}=.31-.67)$ were reported in a sample of daily smokers and nonsmokers (Zvielli et al., 2014). Task modifications may also be explored to improve reliability in measuring attentional bias indices. For example, altering task display and stimulus presentation onset parameters or increasing the number of congruent trials per session instead of repeated administration of the task may yield more reliable scores (Cooper et al., 2011; Enock et al., 2014; Waechter et al., 2013; Waechter \& Stolz, 2015).

Researchers are encouraged to continue to develop and evaluate alternative methods for measuring attentional threat bias using the dot probe task or other tasks. For example, the use of eye tracking methods instead of mouse click reaction times on the dot probe task may lead to more reliable measurement of attentional threat bias. Waechter et al. (2015) found an attention bias index measured by eye tracking indices on a free-viewing task had higher internal consistency reliability ( $\alpha=.58$ to .69 ) than attentional threat bias scores $(\alpha=-.55$ to .38$)$ in undergraduate students scoring high and low on a social anxiety measure. However, Price et al. (2015) reported low internal consistency reliability of attention bias indices calculated using eye tracking methods (ICCs $=.08-.33$ ) during the dot probe task in healthy children and adolescents.

Measures of neural activity, such as event-related potentials, in response to threatening stimuli represent another option for measuring attention to threat on the dot probe. Neural activity in response to threatening stimuli provides a more proximal, less distal, measure of attention than behavioral responses to threatening stimuli . Further, neural activity may provide a more reliable estimate of attention to threat than behavioral responses because, unlike behavioral responses, neural activity is not subject to variability in motor response and strategic decision making (MacNamara, Kappenman, Black, Bress, \& Hajcak, 2012). 
In summary, the present study provides evidence of low split-half reliability and test-retest reliability of the attentional threat bias index and low test-retest reliability of the ABV index measured using the dot probe task in clinic referred children and adolescents with anxiety disorders. Future research is encouraged to explore alternative approaches to measuring threat-related attention on the dot probe task and to develop and evaluate novel paradigms for measuring attention to threat. 


\section{LONG-TERM FOLLOW-UP OF ATTENTION BIAS MODIFICATION TREATMENT IN ANXIOUS YOUTH}

This manuscript will be submitted to the Journal of Anxiety Disorders and thus adheres to its use of APA $6^{\text {th }}$ Edition formatting guidelines.

Melendez, R., and Pettit., J. W. (in preparation). Long-term follow-up of attention bias modification treatment in anxious youth 


\begin{abstract}
There are no data regarding long-term outcomes of attention bias modification treatment (ABMT), a computer-administered intervention for anxiety derived from attentional processing theory, in youth. Using a multisource assessment approach, the present study examined long-term outcomes of ABMT as a standalone or adjunctive treatment in 74 youth (ages 9 to 22) one to six years (average four years) following their last in-clinic assessment at an anxiety disorders specialty clinic. Three groups of youth were identified: 1) 12 youth who were assessed only; 2) 34 youth who completed ABMT only; and 3) 28 youth who completed ABMT followed by CBT. Multiple pairwise binary logistic regressions and analyses of covariance indicated that at LTFU, the assessed only, ABMT, and ABMT+CBT groups were statistically indistinguishable with respect to diagnostic recovery status, anxiety symptoms, anxiety-related impairment, and attentional control. Separate hierarchical regressions indicated that attentional control, attention bias variability, minority status, anxiety symptoms, and anxiety symptom severity at pre-assessment were not predictive of outcomes at post-assessment or LTFU for the ABMT group. Although present findings regarding predictors of outcomes are unclear, overall anxiety levels and functioning at LTFU provide a promising outlook on the clinical utility of ABMT. Future research is encouraged to expand on these findings by further examining efficacy and predictors of outcomes in youth within the context of a controlled trial.
\end{abstract}

Keywords: Attention Bias Modification Treatment; Attentional Control; Attention Bias Variability; Children; Adolescent; Anxiety. 
Long-Term Follow-Up of Attention Bias Modification Treatment in Anxious Youth Introduction

Anxiety disorders are among the most prevalent and impairing psychiatric disorders among youth (Costello, Egger, Angold, \& Clinics, 2005; Silverman \& Field, 2011). Further, research indicates that early onset anxiety typically persists over time if left untreated (Dekovic, Buist, \& Reitz, 2004; Sterba, Prinstein, \& Cox, 2007). Attention Bias Modification Treatment (ABMT) is a recently developed computeradministered treatment for anxiety disorders rooted in cognitive neuroscience (Bar-Haim, 2010). Researchers are enthusiastic about ABMT because it is brief, highly portable, and can be delivered by paraprofessionals. Researchers are also enthusiastic because ABMT offers an alternative or an adjunct to existing evidence-based treatments for anxiety. There is critical need for alternative and adjunctive treatments because up to $50 \%$ of youth with anxiety disorders show insufficient response to existing evidence-based treatments, including cognitive behavioral therapy and antidepressant medications.

The current study presents the first long-term follow-up data on ABMT for youth with anxiety disorders. In the following sections, I present the theoretical and empirical rationale for ABMT and then review evidence on the efficacy of ABMT for youth anxiety.

\section{Perturbations in Attentional Processing in Anxiety Disorders}

Evidence from behavioral neuroscience and information processing research implicates threatrelated attention bias and attentional control in the etiology and maintenance of anxiety (Bar-Haim, Lamy, Pergamin, Bakermans-Kranenburg, \& Van, 2007; Bradley, Mogg, Falla, \& Hamilton, 1998; Derryberry \& Reed, 2002; Heeren, De Raedt, Koster, \& Philippot, 2013; Mathews \& MacLeod, 2002). Threat-related attention bias is preferential attention to threatening over neutral stimuli in the immediate environment (MacLeod, Mathews, \& Tata, 1986). According to neuroimaging and behavioral studies, attention

orientation towards threat occurs rapidly and below awareness (Monk et al., 2006; Monk et al., 2008) and is associated with heightened activation in the amygdala; subsequent activation of the lateral prefrontal cortex corresponds to strategic attentional control and serves to regulate emotion in the face of stimuli perceived as threatening (Browning, Holmes, Murphy, Goodwin, \& Harmer, 2010; Davis \& Whalen, 2001; Hariri, 
Mattay, Tessitore, Fera, \& Weinberger, 2003; Monk et al., 2006; Monk et al., 2008; Nomura et al., 2004). Research documents these phenomena among youth (Heim-Dreger, Kohlmann, Eschenbeck, \& Burkhardt, 2006; Lonigan, Vasey, Phillips, \& Hazen, 2004; Telzer et al., 2008; Vasey, El-Hag, \& Daleiden, 1996) and adults (Bradley et al., 1998; Mogg \& Bradley, 1999, 2002, 2006) presenting with subclinical anxiety as well as youth (Vasey, Daleiden, Williams, \& Brown, 1995; Waters, Henry, Mogg, Bradley, \& Pine, 2010; Waters, Mogg, Bradley, \& Pine, 2008) and adults (Bradley, Mogg, White, Groom, \& Bono, 1999; Mogg, Philippot, \& Bradley, 2004; Sposari \& Rapee, 2007) with anxiety disorders.

Attentional control theory posits that anxiety is associated with impairment in attentional control, which in turn increases threat-related attention bias (Derakshan \& Eysenck, 2009; Eysenck \& Derakshan, 2011; Eysenck, Derakshan, Santos, \& Calvo, 2007). Attentional control is defined as the ability to voluntarily and strategically focus, sustain, and shift attention (Derryberry \& Reed, 2002). Low levels of attentional control have been significantly associated with anxiety disorders (Lonigan et al., 2004; Muris \& Ollendick, 2005; Susa, Pitica, Benga, \& Miclea, 2012). Among youth and young adults, attentional control has been shown to moderate the relationship between threat-related attention bias and trait anxiety (Cisler \& Koster, 2010; Derryberry \& Reed, 2002).

\section{Attention Bias Modification Treatment for Anxiety Disorders}

Attention bias modification treatment is the direct translational treatment implication of perturbed attentional processing in anxiety disorders. Attention bias modification treatment is a computeradministered treatment protocol based on research showing the attention of anxious individuals can be shaped and modified via repetitive, computer training (Hakamata et al., 2010; Lowther \& Newman, 2014). The visual probe-detection paradigm is the most commonly used task to measure and modify threat-related attention bias. The computer task simultaneously presents threatening (e.g., angry face) and nonthreatening (e.g., neutral face) stimuli, which are followed by a probe (e.g., a dot). The probe replaces the threatening face on some trials and the neutral face on others. Individuals are instructed to identify the probe as quickly as possible by clicking a mouse button using their dominant hand. Response latency is used to calculate an index of attention bias such that longer reaction times when the probe replaces the nonthreatening stimulus relative to the threatening stimulus indicate preferential attention to the threatening 
stimulus over the non-threatening one. Attention bias variability (ABV), an alternative calculation method that conceptualizes directional variability of attention bias as a marker of perturbed attentional processing, has demonstrated superior reliability to the traditional AB calculation method (Iacoviello, 2014; Price et al., 2015).

In ABMT, the probe is always or almost always placed behind the non-threatening stimulus to train attention toward non-threatening stimuli over hundreds of trials. In contrast to traditional psychosocial treatments that emphasize top down strategies (Clark \& Beck, 2010; Southam-Gerow \& Kendall, 2000), ABMT targets bottom up, automatic attentional processes (Ledoux, 1996) using a repetitive, computer based training paradigm affecting subcortical and frontal-cortical circuitry (Browning et al., 2010; Eldar et al., 2012; Hakamata et al., 2010). Compared with traditional psychosocial treatments for anxiety, ABMT requires less time and personal investment from patients and does not require highly skilled clinicians. Further, the computer delivery format of ABMT may circumvent the difficulty of engaging children in treatment, as is sometimes the case in traditional talking therapies and exposure-focused treatment approaches (Lowther \& Newman, 2014).

Research supports the short-term efficacy of ABMT in ameliorating anxiety symptom severity and anxiety diagnosis among adults (Bar-Haim, 2010; Hakamata et al., 2010; Lowther \& Newman, 2014; Macleod \& Clarke, 2015; Mogoase, David, \& Koster, 2014; Price et al., 2016) and youth (Bar-Haim, 2010; Eldar et al., 2012; Lowther \& Newman, 2014; Riemann, Kuckertz, Rozenman, Weersing, \& Amir, 2013; Rozenman, Weersing, \& Amir, 2011; Shechner et al., 2014). A systematic literature review of 10 studies on ABMT conducted with youth diagnosed with an anxiety disorder also noted significant pre-treatment to immediate post-treatment reductions in anxiety severity and significant reductions in threat-related attention bias (Lowther \& Newman, 2014). Evidence generally indicates that ABMT leads to reductions in threat-related attention bias (Amir, Beard, Burns, \& Bomyea, 2009; Amir, Beard, Taylor, et al., 2009; BarHaim, 2010; Hakamata et al., 2010; Klumpp \& Amir, 2010; Kuckertz \& Amir, 2015; Lowther \& Newman, 2014; McNally, Enock, Tsai, \& Tousian, 2013; Mogoase et al., 2014; Pettit et al., 2019; Pettit et al., 2017) and increases in attentional control (Chen, Clarke, Watson, MacLeod, \& Guastella, 2015; Heeren, Mogoase, McNally, Schmitz, \& Philippot, 2015; McNally et al., 2013; Pettit et al., 2019), and that shifts in 
attentional threat bias and attentional control are significantly associated with reductions in anxiety (Amir, Beard, Taylor, et al., 2009; Clarke, Notebaert, \& MacLeod, 2014; Hakamata et al., 2010; Kuckertz et al., 2014; Pettit et al., 2019).

Research also supports the short-term efficacy of ABMT as an adjunctive treatment to CBT in youth (White et al., 2017). Across outpatient and residential settings, ABMT administered concurrently with CBT has yielded anxiety symptom reduction superior to control training in youth as well as improved attentional control (Riemann et al., 2013; Shechner et al., 2014). Further, use of ABMT as a CBT augmentation strategy in youth with CBT-resistant anxiety disorders resulted in statistically significant anxiety symptom reductions, over 50\% diagnostic recovery, and statistically significant increases in attentional control (Pettit et al., 2019).

\section{Present Study}

In spite of data supporting the short-term efficacy of ABMT for youth with anxiety disorders, no study has investigated the maintenance of ABMT's effects over time, either as a standalone treatment or an adjunct to CBT. Further, no study has investigated variables that predict long-term outcomes following a course of ABMT (Lowther \& Newman, 2014; Roy, Dennis, \& Warner, 2015). Follow-up assessments of youth who participated in trials of ABMT have extended no further than three months beyond immediate post-treatment (Ollendick et al., 2018; Pergamin-Hight, Pine, Fox, Bar-Haim, \& Psychiatry, 2016). Only one study has examined predictors of acute response to ABMT in adults (Amir et al., 2011), finding that racial/ethnic minority status and a higher attention bias to threat significantly predicted better acute response to ABMT (Amir, Taylor, \& Donohue, 2011). No studies have examined predictors of long-term outcomes in youth. The absence of data on long-term outcomes following ABMT and predictors of longterm outcomes represents an important gap in the knowledge base because such data would 1) shed light on the maintenance of gains following a course of ABMT and 2) identify youth who are most likely to experience sustained benefits from this novel treatment. Comparison of long-term outcomes between $\mathrm{ABMT}$ as a standalone and as an adjunct to $\mathrm{CBT}$ would also provide data to inform the optimal utilization of ABMT for long-term reductions in anxiety. 
The present study leveraged data collected from services at a youth anxiety disorders specialty clinic to examine long-term outcomes in youth who completed ABMT as a standalone treatment or as an adjunctive treatment to CBT. Specifically, we identified three groups of youth: 1) youth who completed a pre-treatment assessment but did not receive any treatment (assessed only group); 2) youth who completed ABMT only (ABMT group); and 3) youth who completed both ABMT and CBT (ABMT+CBT group). We addressed the following questions at a long-term follow-up evaluation (LTFU): 1) Do youth who completed ABMT only or together with CBT show significantly higher diagnostic recovery rates than youth who did not complete treatment?; 2) Do youth who completed ABMT only or together with CBT show significantly better scores on measures of anxiety symptoms, functional impairment, and attentional control?; 3) Do youth who completed ABMT only significantly differ from youth who completed ABMT with CBT on diagnostic recovery, anxiety symptoms, functional impairment, and attentional control?; and 4) What variables measured at a pre-treatment assessment predict outcomes at post-assessment and LTFU in youth who completed ABMT only?

Given prior support for ABMT's acute anxiety reduction effects, we expected that at LTFU, youth who completed ABMT as a standalone or adjunctive treatment would show superior diagnostic recovery rates to youth who were assessed only. In light of the augmentative effects of ABMT coupled with the persistent trajectory of untreated anxiety, we expected youth who completed both ABMT and CBT to report lower levels of anxiety symptoms and functional impairment, and higher levels of attentional control compared to youth who completed ABMT only and youth who received no treatment. Finally, expanding on data regarding predictors in adult outcomes, we expected that higher levels of anxiety and functional impairment, lower levels of attentional control, and higher attention bias variability at pre-assessment as well as minority status would predict poorer outcomes at post-assessment and LTFU in the ABMT group. Corroborating previous evidence of the efficacy of ABMT as a treatment for anxious youth and identifying predictors of long-term outcomes would assist in further expanding the knowledge base of this least restrictive treatment and identifying for whom ABMT may be most beneficial as an adjunctive or standalone treatment. 


\section{Method}

\section{Participants}

I identified 171 youths who were eligible and attempted to contact their families. Of the 171, 51 (29.82\%) could not be reached. Of the 120 families who were reached, $95(79.17 \%)$ agreed to participate in the study. Of those, 21 participants (22.11\%) expressed interest but ultimately did not participate as a result of scheduling or time constraints. Participants included 74 youth who completed a pre-treatment assessment within the previous one to six years at a university-based anxiety disorders specialty clinic in an urban setting. Of these 74 youth, 12 were assessed only, 34 completed ABMT, and 28 completed ABMT and CBT (Figure 2). All participants were also asked whether they had received alternative treatment following their last visit to the clinic. Of these participants, $10(14 \%)$ had received further treatment for an anxiety-related problem, including previous $(\mathrm{N}=8,11 \%)$ or current $(\mathrm{N}=6,8 \%)$ psychosocial treatment and previous $(\mathrm{N}=7,10 \%)$ or current $(\mathrm{N}=7,10 \%)$ medication treatment.

The 74 participants ( $51 \%$ girls) ranged in age from 9 to 22 years $\left(\mathrm{Mean}_{\text {age }}=13.97, \mathrm{SD}_{\text {age }}=2.63\right)$, with the average length of time since treatment completion being 3.93 years (range $=0.90-5.51$ years, $\mathrm{SD}=0.92$ ). Approximately $85 \%$ of the sample identified as Hispanic/Latino, $10 \%$ as White European, $2 \%$ as Black, and 3\% as Other race/ethnicity. Parents reported annual household income as follows: $7.60 \%$ below $\$ 20,999 ; 27.30 \%$ between $\$ 21,000$ and $\$ 40,999 ; 19.70 \%$ between $\$ 41,000$ and $\$ 60,999 ; 13.60 \%$ between $\$ 61,000$ and $\$ 80,999 ; 6.10 \%$ between $\$ 81,000$ and $\$ 99,999 ; 16.70 \%$ between $\$ 100,000$ and $\$ 149,000$; and $7.60 \%$ over $\$ 150,000$. Finally, $1.40 \%$ did not report on income.

\section{Treatments}

Prior to treatment, all youth completed a pre-treatment assessment across two visits approximately one week apart consisting of the following: parent and youth report of anxiety symptoms, youth report of attentional control, computer assessment of threat-related attention bias, and semi-structured clinical interview with parent and child.

$\boldsymbol{A B M T}$. Treatment consisted of eight 15-minute sessions of ABMT, administered by a masters or doctoral level student, twice weekly across four weeks. Posttreatment assessment occurred one week following the final session of ABMT and consisted of the following: parent and youth report of anxiety 
symptoms, youth report of attentional control, and computer assessment of threat-related attention bias. All participants completed eight sessions of ABMT.

$\boldsymbol{C B T}$. Following the ABMT posttreatment assessment, families were offered the option to complete CBT. Individual CBT consisted of weekly sessions administered by a masters or doctoral level student. On average, participants completed 11 sessions of $\mathrm{CBT}\left(\right.$ Mean $_{\mathrm{CBTSessions}}=11.32, \mathrm{SD}_{\mathrm{CBTSessions}}=$ 2.48). Sessions were 60 minutes in duration and targeted anxiety symptoms using cognitive restructuring and exposures in line with a treatment manual developed in a previous CBT trial (Silverman, Kurtines, Jaccard, \& Pina, 2009). Posttreatment assessment occurred one week following the final session of CBT and consisted of the following: parent and youth report of anxiety symptoms, youth report of attentional control, and computer assessment of threat-related attention bias.

\section{Measures}

\section{Measures completed by children.}

\section{Screen for Child Anxiety Related Emotional Disorders - Child Version (SCARED-C; Birmaher}

et al., 1999; Birmaher et al., 1997). The SCARED-C is a 41-item youth self report measure assessing anxiety symptom severity. The SCARED-C has demonstrated satisfactory to excellent test-retest reliability, is sensitive to change, and is internally reliable (Bar-Haim, Morag, \& Glickman, 2011; Birmaher et al., 1999; Birmaher et al., 1997; Monga et al., 2000). The SCARED-C has also demonstrated good convergent and divergent validity compared with formal psychiatric diagnoses, structured psychiatric interviews, and other widely used screening scales (Monga et al., 2000). In accordance with past ABMT research (Pettit et al., 2019; Pettit et al., 2017) the SCARED-C total score was used in analyses. In this sample, the alpha coefficient was 0.94 .

Columbia Impairment Scale - Child Version (CIS; Bird, Shaffer, Fisher, \& Gould, 1993). The CIS is a 13-item youth self report scale that assesses youth functional impairment. Responses are scored on a 4-point Likert scale that ranges from 0 (No problem) to 4 (Very bad problem). Responses are summed such that higher scores indicate more functional impairment. The CIS has demonstrated significant associations between clinician children's global assessment score (CGAS) as well as good construct and discriminant validity (Bird et al., 1996). The alpha coefficient was 0.80 for this sample. 
Attentional Control Scale for Children (ACS-C; Peter Muris, de Jong, \& Engelen, 2004). The ACS-C is a 20 -item youth self report scale that assesses abilities to voluntarily focus and shift attention. Regarding convergent validity, significant associations have been reported between ACS-C scores and performance based measures of attention (Muris, Mayer, Lint, \& Hofman, 2008). Regarding concurrent validity, cross-sectional associations have been reported between ACS-C scores and parent and youth self report on measures of youth anxiety symptom severity (Melendez, Bechor, Rey, Pettit, \& Silverman, 2017; Muris et al., 2004; Muris et al., 2008; Muris, Meesters, \& Rompelberg, 2007), youth depressive symptom severity (Muris et al., 2008; Muris et al., 2007), and youth ADHD symptom severity (Muris et al., 2008; Muris et al., 2007). The alpha coefficient in the present sample was 0.80 .

Dot Probe Task. Participants were administered the visual dot probe task modified for youth (TAU-NIMH ABMT initiative; http://tau.ac.il/ yair1/ABMT.html) on a laptop with a 17 inch monitor using E-Prime software (Psychology Software Tools, Inc., Sharpsburg, PA) at pre-treatment assessment. Participants were instructed to respond as quickly and as accurately as possible by clicking mouse pad buttons using only their dominant hand. The task was comprised of 120 trials. A visual depiction of a trial is available in Figure 1. During the dot probe task, a centered fixation cross appeared first for 500 milliseconds (ms), followed by a pair of vertically oriented faces presented for $500 \mathrm{~ms}$. Facial stimuli were images of the same actor emoting either a neutral or threatening expression. Facial stimuli were presented in one of the following possible pairs: neutral-anger, anger-neutral, or neutral-neutral. A visual probe (“<” or ">") appeared behind the top or bottom stimulus and remained visible until participants indicated the direction of the probe by clicking the left (“<”) or right (">”) mouse button using their dominant hand. Probes that appeared at the location of the angry face were considered congruent trials and probes that appeared at the location of the neutral face were considered incongruent trials. Participants were instructed to indicate the type of probe ("<" or ">>) by pressing either the left or the right mouse button with their dominant hand. The probe remained on screen until the participants responded. The subsequent trial began immediately following participant response. In addition to the assessor delivering instructions prior to beginning the task, all task instructions appeared on the computer screen prior to the first trial. 
The faces used in the probe detection task were selected from the Tel Aviv University - NIMH ABMT Initiative (http://people.socsci.tau.ac.il/mu/anxietytrauma/research/; Abend, Pine, \& Bar-Haim, 2014). The set of stimuli included ten White actors selected from the NimStim set of facial expressions (Tottenham et al., 2009) displaying angry or neutral expressions. Each face was $34 \mathrm{~mm}$ in height and $47 \mathrm{~mm}$ in width. Responses on the dot-probe task were used to calculate the attention bias variability index, described below. Although examinations of convergent validity with measures of anxiety have yielded mixed results (Price et al., 2015), evidence supports the validity of the dot probe task in distinguishing between individuals who meet diagnostic criteria for an anxiety disorder (Bar-Haim et al., 2007).

Attention Bias Variability Index. An ABV index was calculated by partitioning threat-neutral trials into six groups of 20 trials each and then calculating the attentional threat bias index for each group (Iacoviello et al., 2014; Price et al., 2015). The standard deviation of the six attentional bias indices was then calculated and divided by participants' mean reaction times across all threat-neutral trials. Responses on neutral-neutral trials and trials with inaccurate responses were excluded.

\section{Measures completed by parents.}

Columbia Impairment Scale - Parent Version (CIS-P; Bird et al., 1993). The CIS-P is a 13-item parent report scale that assesses youth functional impairment. Scores on the CIS-P have been shown to be significantly associated with clinician ratings of impairment (Bird et al., 1996). The alpha coefficient for this sample was 0.83 .

\section{Screen for Child Anxiety Related Emotional Disorders - Parent Version (SCARED-P;}

Birmaher et al., 1999; Birmaher et al., 1997). The SCARED-P is a 41-item parent report measure assessing anxiety symptom severity. Parent ratings represent important additional outcomes in youth anxiety trials (Klein, Dougherty, \& Olino, 2005; Silverman \& Ollendick, 2005). The reliability and validity of the SCARED-P mirror those of the SCARED-C (Birmaher et al., 1999; Birmaher et al., 1997; Monga et al., 2000). In this sample, the alpha coefficient was 0.94 .

\section{Additional Measures.}

Pediatric Anxiety Rating Scale (PARS; RUPP Anxiety Study Group, 2002). The PARS is a clinician-rated instrument for assessing anxiety symptom severity. Six items assessing anxiety severity, 
frequency, distress, avoidance, and interference during the previous week are summed to provide a total score ranging from 0 to 30 . Scores above 13 are considered to indicate clinically meaningful anxiety. The PARS has demonstrated adequate internal consistency, interrater reliability, and convergent validity with parent and youth ratings of anxiety (RUPP Anxiety Study Group, 2002; Walkup et al., 2008). All parent

and youth dyads were administered the PARS at pre-treatment assessment, post-treatment assessment, and long-term follow-up.

\section{Anxiety Disorders Interview Schedule for DSM-IV-Child/Parent Versions (ADIS-IV: C/P;}

Silverman \& Albano, 1996). In accordance with previous clinical trials for youth anxiety, the ADIS-IV: $\mathrm{C} / \mathrm{P}$ was administered to diagnose youth anxiety disorders. All youths and their parents (usually mothers) were administered the ADIS-IV: C/P at pre-treatment assessment. The ADIS-IV: C/P was also administered at long-term follow-up to determine ongoing or new presence of anxiety disorder and other disorder diagnoses.

Anxiety Disorder Diagnostic Status. Long-term follow-up effects for anxiety disorders was defined as the presence versus absence of DSM anxiety disorders. Rates of anxiety disorders at the LTFU were calculated using ADIS-IV: C/P results for the a) primary anxiety disorder at pre-treatment (i.e., whether or not the primary disorder at the pre-treatment assessment is still present at the LTFU), b) any comorbid anxiety disorder present at pre-treatment assessment, and (c) any new onset anxiety disorder.

Anxiety Sequelae. The development of new psychiatric disorders (MDD, dysthymia, SUD) was defined as meeting DSM criteria for a new onset psychiatric disorder that was not present at either pretreatment assessment or immediate post-treatment assessment.

Treatment History and Utilization. Families were assessed via questions to identify youth who 1) participated in psychosocial or medication treatment following their last visit to our clinic and 2) were receiving ongoing psychosocial or medication treatment at the time of LTFU (Kolko, Brent, Baugher, Bridge, \& Birmaher, 2000). Responses were collapsed to reflect four treatment variables: past medication since the last date of contact with our clinic, past psychosocial treatment since the last date of contact with 
our clinic, current medication, and current psychotherapy. These variables were included as covariates in analyses.

\section{Procedures}

Youth and their families were recruited using telephone information collected from pretreatment assessment. Telephone interviews were scheduled with the study clinician and youth and parent dyads, typically the youth and their mother, consisting of the ADIS-IV: C/P and PARS. Consent forms and questionnaires were made available to be completed online by families using browser-based electronic data capture software REDCap (Research Electronic Data Capture). Upon completion of data collection, families were compensated with a $\$ 20$ gift card. The present study was approved by the Institutional Review Board at Florida International University.

\section{Statistical Analysis}

I performed statistical analyses using the SPSS statistical software program version 24.

Approximately $16.44 \%$ of all data values were missing. In the assessed only group, approximately $38.46 \%$ of data values were missing, compared to $25.70 \%$ of missing data values in the ABMT only group and $24.86 \%$ of missing data values in the ABMT+CBT group. Rates of missing data were as follows for the following outcome measures: $33.78 \%$ of ACS-C at LTFU; $32.43 \%$ of CIS-C at LTFU; $32.43 \%$ of SCARED-C at LTFU; $24.32 \%$ of CIS-P at ABMT Post; $22.97 \%$ of CIS-C at ABMT Post; $16.22 \%$ of PARS at LTFU; $10.81 \%$ of PARS at ABMT Post; $10.81 \%$ of ACS-C at ABMT Post; $10.81 \%$ of CIS-P at LTFU; $10.81 \%$ of SCARED-P at LTFU; $9.46 \%$ of SCARED-C at ABMT Post; and 9.46\% of SCARED-P at ABMT Post. Missingness was accommodated using fully conditional specification multiple imputation (Enders, Keller, \& Levy, 2017; Keller \& Enders, 2017).

\section{Results}

Multiple pairwise analyses of variance (ANOVA; Jaccard \& Guilamo-Ramos, 2002) revealed that participants from all three groups were statistically indistinguishable in terms of sociodemographic (i.e., age, gender, ethnicity, family income) and pre-treatment clinical variables (i.e., parent report of anxiety, youth self report of attentional control, clinician ratings of functional impairment, and number of pretreatment diagnoses). Child report of anxiety severity at pre-treatment assessment intake indicated 
significantly greater anxiety severity in ABMT+CBT youth $\left(\right.$ Mean $\left._{C I S-C}=27.48\right)$ than youth who completed ABMT $\left(\right.$ Mean $\left._{C I S-C}=14.17 ; \mathrm{F}[1,61]=11.74, \mathrm{p}<.01\right)$ or no treatment $\left(\right.$ Mean $_{C I S-C}=7.26 ; \mathrm{F}[1,39]=16.65, \mathrm{p}$ $=.02$ ). No significant differences were noted between youth who completed ABMT and youth who did not participate in treatment. Finally, no differences in sociodemographic and pre-treatment clinical variables were observed between families who participated and families who declined to participate.

\section{Aim 1: Diagnostic recovery status at LTFU}

Of the 34 youth who completed ABMT only, $15(44 \%)$ met criteria for at least one disorder at LTFU. Of these 15 youth, one (7\%) retained their primary diagnosis from pre-treatment assessment, seven (47\%) retained another, non-primary diagnosis from pre-treatment assessment, and seven (47\%) met criteria for a new anxiety disorder not present on their diagnostic profile at pre-treatment assessment. Overall, approximately $38 \%$ of ABMT youth met criteria for generalized anxiety disorder (GAD), $18 \%$ for social phobia, $6 \%$ for specific phobia, and $6 \%$ for major depressive disorder.

Regarding the 28 youth who completed ABMT+CBT, 15 (54\%) met criteria for at least one anxiety disorder at LTFU. Of these 15 , six (40\%) retained their primary diagnosis from pre-treatment assessment, five (33\%) retained another, non-primary diagnosis from pre-treatment assessment, and four (27\%) met criteria for a new anxiety disorder not present on their diagnostic profile at pre-treatment assessment. Overall, approximately $36 \%$ of ABMT+CBT youth met criteria for GAD, $36 \%$ for social phobia, and $7 \%$ for specific phobia.

Of the 12 youth who did not complete treatment, four (33\%) met criteria for at least one anxiety disorder at LTFU. Of these four, one (25\%) retained their primary diagnosis from pre-treatment assessment, three $(75 \%)$ retained another, non-primary diagnosis from pre-treatment assessment, and none met criteria for a new anxiety disorder not present on their diagnostic profile at pre-treatment assessment. Approximately $8 \%$ of non-treated youth met criteria for GAD and 33\% for social phobia.

Multiple pairwise binary logistic regressions were performed to examine the relationships between treatment condition and presence of an anxiety disorder, retainment of primary diagnosis, and development of anxiety sequelae at LTFU while adjusting for time elapsed since post-assessment and utilization of 
psychosocial treatments and medication use after post-assessment. None of the relationships were statistically significant. Results are presented in Table 4.

\section{Aim 2: Comparison of outcomes on treatment targets at LTFU between treatment groups}

Multiple pairwise analyses of covariance (ANCOVA) were performed to examine whether anxiety symptoms (SCARED-C/P), anxiety impairment (PARS; CIS-C/P), and attentional control (ACS-C) were significantly different between treatment conditions at LTFU. Covariates in each analysis included time elapsed since participants' previous assessment at CAPP as well as their respective baseline severity on the measure of interest. No significant between-group differences were observed at LTFU on any measures. Results are presented in Tables 5 through 7.

Descriptive statistics for individual group measures are provided in Table 8. Parent and child ratings of anxiety symptoms fell below recommended clinical cutoffs across all groups at LTFU, indicating levels of anxiety comparable to the general population. Parent, child, and clinician ratings of anxiety related impairment fell below recommended clinical cutoffs across all groups. Finally, scores on self-report ratings of attentional control were uniformly high at LTFU.

\section{Aim 3: Predictors of outcome at post and LTFU in ABMT only condition}

Separate hierarchical regressions were performed to examine whether measures collected at pretreatment assessment were predictive of outcomes for ABMT only youth at post and at LTFU. Specifically, anxiety symptoms (SCARED-C/P), anxiety symptom severity (PARS), attention bias variability, and attentional control were examined. Outcome variables consisted of parent and youth report of anxiety symptoms (SCARED-C/P), anxiety impairment (CIS-C/P), and clinician rating of anxiety symptoms and related impairment (PARS). Minority status was also examined as a predictor of outcomes at LTFU, given previous research in adult populations (Amir et al., 2011). In each regression, the first step included the measure of interest at long-term follow-up and baseline severity at pre-treatment assessment intake on the measure of interest. The second step included all previous variables with the addition of the predictor variable of interest. 
Minority status, attention bias variability, and attentional control did not significantly predict outcomes measured at post or LTFU. Neither anxiety symptoms nor anxiety symptom severity as measured at pre-treatment assessment predicted outcomes at post or LTFU.

\section{Discussion}

The current study presents findings for long-term outcomes of non-treated youth and youth who participated in ABMT as either a standalone or adjunctive treatment to CBT. At LTFU, overall anxiety severity as reported by parents and youth fell below clinical cutoffs. Similarly, parent, child, and clinician rated impairment related to anxiety symptoms overall indicated low impairment. Further, the majority of youth did not meet diagnostic criteria for any anxiety disorder at LTFU. Regarding attentional control, selfreport ratings were high.

Approximately four years after completing a four-week course of ABMT, 56\% of youth no longer met diagnostic criteria for an anxiety disorder. Per youth self-report, youth also exhibited high levels of attentional control. Overall, youth who completed ABMT only did not differ significantly from youth who also completed CBT with respect to diagnostic recovery rates. In both conditions, more than half of youth did not meet diagnostic criteria for an anxiety disorder at LTFU. Although this is lower than other reports of long-term remission rates for CBT for anxiety in youth (Saavedra, Silverman, Morgan-Lopez, \& Kurtines, 2010), parent and youth ratings nevertheless indicated overall low levels of impairment. The

present study also provides important new findings with respect to anxiety sequelae at LTFU - compared to youth who completed ABMT and CBT, youth who completed ABMT alone were not more likely to have developed a new anxiety disorder or mood disorder by LTFU.

In addition to diagnostic recovery rates, we examined parent and youth report of anxiety symptoms, functional impairment, and attentional control between groups at LTFU. Overall, youth who completed ABMT alone as opposed to ABMT and CBT were not significantly different in their report of anxiety symptoms, functional impairment, and attentional control, per parent and youth report, at LTFU. That is, completing ABMT as a standalone treatment did not result in poorer long-term gains to completing ABMT as an adjunctive treatment. Although the present findings do not speak to the augmentative effects 
of ABMT on CBT, the overall low levels of anxiety and impairment in the present group provide further evidence for the viability of ABMT as a brief, low-cost, standalone intervention.

Findings regarding predictors of long-term follow-up outcomes were not as clear. No significant relationships were observed with respect to anxiety severity, attention bias variability, and attentional control at pre and treatment outcomes at LTFU. The clinic-referred nature of the sample may have resulted in restricted ranges of scores on measures of anxiety symptoms, functional impairment, and attentional control at pre-treatment assessment. Indeed, with the exception of child rated anxiety severity, variation in pre-treatment assessment scores was not significantly different between groups of youth.

Results from the current study should be interpreted in light of its limitations. Firstly, because results were leveraged using previous clinical services data from an outpatient clinic, participants were not randomized to treatment arms and assessors were not masked to participants' treatment condition at the posttreatment and LTFU assessment visits. Coupled with this, the absence of a placebo condition, given ethical considerations of withholding treatment long-term, make drawing conclusions about the long-term comparative efficacy of ABMT as a standalone versus adjunctive treatment to CBT difficult. Factors not assessed in the present study that may be associated with participants' self-selection into different conditions may confound the present results; however, present methodology of allowing families to select to continue or discontinue treatment resembles the approach of real-world clinical settings. In line with this, difficulties with recruitment at LTFU should not be overlooked. Despite significant effort to contact parents and youth, only $43 \%$ of the eligible families ultimately participated in the LTFU. This is lower than percentages reported in previous long-term outcomes studies of CBT (81\%; Saavedra et al., 2010); however, examination of sociodemographic and pre-treatment clinical variables yielded no differences between families who did and did not participate at LTFU.

Additional consideration is warranted with respect to limitations on interpreting outcomes by treatment condition. Given the small sample sizes across all groups, particularly the assessed only group, analyses were underpowered for detecting statistically significant differences between treatment conditions. Restrictions on power and ability to detect effects between groups should also be considered in the context of predictor variables with limited variability. For example, the large proportion of youth identifying as a 
racial/ethnic minority may have obscured relationships between minority status and treatment outcomes that have been detected in more diverse adult samples (Amir et al., 2011). The unique ethnic composition of this sample also raises questions about generalizability to other racial/ethnic groups. Finally, sample size also precluded the possibility of more fine-grained analyses, such as assessing between-groups differences based on specific anxiety disorders or moderators of outcome at LTFU.

In conclusion, the present study provides further data on the use of ABMT as a standalone and adjunctive treatment for anxiety, specifically in anxious youth. The diagnostic recovery rate of over half of youth completing ABMT only at LTFU supports efficacy for a subset of youth diagnosed with an anxiety disorder. Further, youth in the ABMT group did not significantly differ from youth who completed both ABMT and CBT, and all youth demonstrated typical levels of anxiety and functioning at LTFU. These preliminary data provide a promising outlook on the long-term effects of ABMT for anxiety whether as a standalone or adjunctive treatment. Coupled with evidence supporting the use of ABMT in cost-effective stepped care approaches, examination of its use in nonclinical environments by paraprofessionals (e.g., school) is encouraged (Yeguez, Page, Rey, Silverman, \& Pettit, 2019). Future research is also encouraged to examine long-term gains and relevant predictors within the context of a randomized clinical trial to better identify individuals that might benefit the most from this least-restrictive treatment. 
Tables and Figures

Table 1. Means of, standard deviations of, and correlations between measured variables

\begin{tabular}{|c|c|c|c|c|c|c|c|}
\hline & 1 & 2 & 3 & 4 & 5 & 6 & 7 \\
\hline 1. ACS-C & - & & & & & & \\
\hline 2. Focusing & $.81^{* *}$ & - & & & & & \\
\hline 3. Shifting & $.87^{* * *}$ & $.42^{* *}$ & - & & & & \\
\hline 4. RCMAS-C & $-.39^{* *}$ & $-.34^{* *}$ & $-.32^{* *}$ & - & & & \\
\hline 5. RCMAS-P & $-.19^{* *}$ & $-.16^{*}$ & $-.21^{* *}$ & $.23^{* *}$ & - & & \\
\hline 6. CDI & $-.35^{* *}$ & $-.29^{* * *}$ & $-.34^{* *}$ & $.72^{* *}$ & $.29^{* *}$ & - & \\
\hline 7. ADHD Dx & $-.24^{* *}$ & $-.21^{* *}$ & $-.22^{*}$ & .10 & $.21^{* *}$ & $.16^{*}$ & - \\
\hline M & 50.71 & 23.00 & 27.54 & 12.34 & 13.63 & 10.40 & - \\
\hline SD & 8.64 & 4.69 & 5.68 & 6.59 & 5.84 & 8.20 & - \\
\hline
\end{tabular}

Notes: $N=186$. ACS-C = Attentional Control Scale for Children; Focusing = ACS-C Attentional Focusing Subscale; Shifting = ACS-C Attentional Shifting Subscale; RCMAS-C = Revised Children's Manifest Anxiety Scale - Child Version; RCMAS-P = Revised Children's Manifest Anxiety Scale Parent Version; CDI = Children's Depression Inventory; ADHD Dx = presence of an ADHD diagnosis. $* \mathrm{p}<.05 ; * * \mathrm{p}<.01$. 
Table 2. Factor loadings of ACS-C items

Item
1. It's very hard for me to concentrate on a difficult lesson if there is a lot of

Focusing

Shifting

noise in the class.
2 . If I have to concen

.55

focusing my attention.

3. When I am working hard on something, I still get distracted by things going on around me.

4. My concentration is good, even when somebody turns the music on.

5. When I concentrate myself, I do not notice what is happening in the room around me.

6. When I am reading in the classroom, I am easily disturbed by other children talking to each other.

7. When I try to concentrate myself, I find it difficult not to think about other things.

8. I find it difficult to concentrate myself when I am excited about something.

9. When I am concentrated, I do not notice that I am hungry or thirsty.

10. When I am doing something, I can easily stop and switch to some other task. 11 . When I have to start a new task, it takes me a while to get really involved in it.

12. When the teacher explains something, I find it difficult to understand and write it down at the same time.

13. When it is necessary, I can become interested in a new topic very quickly. 14. It is easy for me to read or write while I am also talking to someone on the telephone.

15. I have trouble having two conversations at the same time.

16. I find it difficult to come up with new ideas quickly.

17. After being interrupted or distracted, I can easily shift my attention back to what I was doing before.

18. When I am daydreaming or having distracting thoughts, it is easy for me to switch back to the work I have to do.

19. It is easy for me to switch back and forth between two different tasks.

20. I find it difficult to let go my own way of thinking about something, and to look at it in a different way.

Initial eigenvalues

Extraction sums of squared loadings

Percentage of variance

Internal consistency

Notes: Items 1, 2, 3, 6, 7, 8, 11, 12, 15, 16, 18, and 20 are reversed for scoring. Items retained in the EFA are bolded.

.58

$-.11$

.65

$-.12$

.21

.19

$-.16$

.62

$-.04$

$\begin{array}{ll}.34 & -.05\end{array}$

$-.03 \quad .06$
-.04

$\begin{array}{ll}-.04 & .40\end{array}$

.58

$\begin{array}{ll}.54 & -.05\end{array}$

$\begin{array}{lll}-.03 & .57\end{array}$

$.03 \quad \mathbf{4 3}$

$.19 \quad .14$

$.30 \quad .12$

$.31 \quad .35$

$.31 \quad .41$

$.16 \quad .60$

$\begin{array}{ll}.40 & -.09\end{array}$

$3.88 \quad 2.14$

$3.18 \quad 1.42$

$15.90 \quad 7.08$

$.77 \quad .64$ 
Table 3. Means of, standard deviations of, and correlations between measured variables

$\begin{array}{llllll}1 & 2 & 3 & 4 & 5 & 6\end{array}$

$6 \quad 7$

1. $\mathrm{AB} 1$

2. $\mathrm{AB} 2$

$-.12$

3. ABV 1

$-.20 *$

.01

4. ABV 2

.04

5. ABV-MA 1

.17

6. ABV-MA 2

.08

7. Age

$-1.98$

-.09
.06

.06

.09

$.21 *$

$-.06$

.16

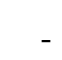

M

-1.98
67.92

$.05 \quad-.27 * *$

$.19 *$

.12

2

$.48 * *$

$-7.55$

.17

$-.15$

.12

$S D$

64.54

.10

.16

$-.28 * *$

.23

$-.05$

.09

.36

1.92

14.10

9.60

Notes: $N=126 . \mathrm{AB} 1=$ Attentional Threat Bias Index at Wave $1 ; \mathrm{AB} 2=$ Attentional Threat Bias Index at Wave 2; ABV 1 = Attention Bias Variability Index at Wave 1; ABV $2=$ Attention Bias Variability Index at Wave 2; ABV-MA $1=$ Attention Bias Variability Index Moving Average at Wave 1; ABV-MA $2=$ Attention Bias Variability Index Moving Average at Wave 2.

$* p<.05 ; * * p<.01$. 
Table 4. Binary logistic regressions examining diagnostic recovery status

\begin{tabular}{|c|c|c|c|c|c|c|c|c|c|}
\hline Group & Variable & B & SE & Wald & df & $p$ & OR & \multicolumn{2}{|c|}{$95 \% \mathrm{CI}$ for $\mathrm{OR}$} \\
\hline & & & & & & & & Lower & Upper \\
\hline \multicolumn{10}{|l|}{ AOx } \\
\hline \multirow[t]{4}{*}{ Anxiety } & Group & 1.61 & 1.56 & 1.30 & 1 & 0.302 & 5.00 & 0.24 & 106.25 \\
\hline & Time & 0.00 & 0.00 & 0.69 & 1 & 0.748 & 1.00 & 1.00 & 1.01 \\
\hline & Past Tx & 1.59 & 1.88 & 1.11 & 1 & 0.398 & 4.90 & 0.12 & 196.96 \\
\hline & Constant & -5.29 & 4.42 & 2.15 & 1 & 0.233 & 0.01 & & \\
\hline \multirow[t]{4}{*}{ Primary Dx } & Group & 1.61 & 1.56 & 1.30 & 1 & 0.302 & 5.00 & 0.24 & 106.25 \\
\hline & Time & 0.00 & 0.00 & 0.69 & 1 & 0.748 & 1.00 & 1.00 & 1.01 \\
\hline & Past Tx & 1.59 & 1.88 & 1.11 & 1 & 0.398 & 4.90 & 0.12 & 196.96 \\
\hline & Constant & -5.29 & 4.42 & 2.15 & 1 & 0.233 & 0.01 & & \\
\hline \multirow[t]{4}{*}{ Sequelae } & Group & -12.72 & 8924.10 & 0.08 & 1 & 0.999 & 0.00 & 0.00 & 4.95 \\
\hline & Time & 0.00 & 0.00 & 1.67 & 1 & 0.376 & 1.00 & 1.00 & 1.01 \\
\hline & Past Tx & -0.50 & 1.27 & 0.26 & 1 & 0.695 & 0.61 & 0.05 & 7.32 \\
\hline & Constant & -4.40 & 3.44 & 2.82 & 1 & 0.203 & 0.01 & & \\
\hline \multicolumn{10}{|l|}{$\begin{array}{l}\text { ABMTx } \\
\text { CBT }\end{array}$} \\
\hline & Group & -0.48 & 0.55 & 0.85 & 1 & 0.377 & 0.62 & 0.21 & 1.80 \\
\hline & Time & 0.00 & 0.00 & 0.97 & 1 & 0.552 & 1.00 & 1.00 & 1.00 \\
\hline & Past Tx & 0.93 & 0.79 & 1.48 & 1 & 0.240 & 2.53 & 0.54 & 11.96 \\
\hline & Constant & -1.07 & 1.81 & 0.87 & 1 & 0.555 & 0.34 & 0.01 & \\
\hline \multirow[t]{4}{*}{ Primary Dx } & Group & -2.720 & 1.470 & 4.46 & 1 & 0.065 & 0.07 & 0.00 & 1.18 \\
\hline & Time & -0.005 & 0.003 & 4.10 & 1 & 0.190 & 1.00 & 0.99 & 1.00 \\
\hline & Past Tx & 3.763 & 1.957 & 6.20 & 1 & 0.057 & 43.07 & 0.90 & 2067.81 \\
\hline & Constant & 4.540 & 4.446 & 2.44 & 1 & 0.311 & 93.72 & 0.01 & \\
\hline \multirow[t]{4}{*}{ Sequelae } & Group & 0.38 & 0.92 & 0.60 & 1 & 0.679 & 1.47 & 0.24 & 9.09 \\
\hline & Time & 0.00 & 0.00 & 2.04 & 1 & 0.389 & 1.00 & 1.00 & 1.01 \\
\hline & Past Tx & -0.76 & 1.21 & 0.56 & 1 & 0.528 & 0.47 & 0.04 & 4.99 \\
\hline & Constant & -4.38 & 2.85 & 4.10 & 1 & 0.126 & 0.01 & 0.00 & \\
\hline \multicolumn{10}{|l|}{$\begin{array}{l}\text { CBTxAO } \\
\text { Anxiety }\end{array}$} \\
\hline & Group & -0.28 & 0.82 & 0.22 & 1 & 0.730 & 0.75 & 0.15 & 3.79 \\
\hline & Time & 0.00 & 0.00 & 0.70 & 1 & 0.512 & 1.00 & 1.00 & 1.00 \\
\hline & Past Tx & 0.59 & 0.90 & 0.52 & 1 & 0.510 & 1.80 & 0.31 & 10.43 \\
\hline & Constant & -1.45 & 1.65 & 1.06 & 1 & 0.381 & 0.24 & 0.01 & \\
\hline \multirow[t]{4}{*}{ Primary Dx } & Group & 1.61 & 1.56 & 1.30 & 1 & 0.302 & 5.00 & 0.24 & 106.25 \\
\hline & Time & 0.00 & 0.00 & 0.69 & 1 & 0.748 & 1.00 & 1.00 & 1.01 \\
\hline & Past Tx & 1.59 & 1.88 & 1.11 & 1 & 0.398 & 4.90 & 0.12 & \\
\hline & Constant & -5.29 & 4.42 & 2.15 & 1 & 0.233 & 0.01 & 0.00 & 30.84 \\
\hline \multirow[t]{4}{*}{ Sequelae } & Group & -12.72 & 8924.10 & 0.08 & 1 & 0.999 & 0.00 & 0.00 & 4.98 \\
\hline & Time & 0.00 & 0.00 & 1.67 & 1 & 0.376 & 1.00 & 1.00 & 1.01 \\
\hline & Past Tx & -0.50 & 1.27 & 0.26 & 1 & 0.695 & 0.61 & 0.05 & 7.32 \\
\hline & Constant & -4.40 & 3.44 & 2.82 & 1 & 0.203 & 0.01 & 0.00 & \\
\hline
\end{tabular}

Note: $\mathrm{AOxABMT}=$ Comparison of assessed only and ABMT only group; $\mathrm{ABMT}$ CBC $=$ Comparison of ABMT only and ABMT+CBT group; $\mathrm{CBTxAO}=$ Comparison of CBT and assessed only group. Anxiety $=$ Presence of any anxiety disorder at long-term follow-up; Primary Dx $=$ Retainment of primary disorder from pre-treatment assessment intake at long-term follow-up; Sequelae $=$ Presence of a new psychiatric disorder at long-term follow-up. 
Table 5. Comparison of outcomes on treatment targets at long-term follow-up between the assessed only and ABMT only groups

\begin{tabular}{|c|c|c|c|c|c|c|c|c|}
\hline \multirow[b]{3}{*}{ Group } & \multirow[b]{3}{*}{$N$} & \multicolumn{3}{|c|}{ Unadjusted } & \multicolumn{3}{|c|}{ Adjusted } & \multirow[b]{3}{*}{$\begin{array}{c}\text { Partial } \\
\eta^{2}\end{array}$} \\
\hline & & \multirow[b]{2}{*}{$M$} & \multirow[b]{2}{*}{$S D$} & \multirow[b]{2}{*}{$M$} & \multicolumn{3}{|c|}{$95 \% \mathrm{CI}$} & \\
\hline & & & & & $S E$ & LB & UB & \\
\hline AOXABMT & & & & & & & & \\
\hline PARS & & & & & & & & 0.02 \\
\hline $\mathrm{AO}$ & 12 & 10.64 & 6.15 & 11.11 & 3.27 & 4.63 & 17.58 & \\
\hline ABMT & 34 & 11.31 & 7.93 & 10.67 & 1.58 & 7.54 & 13.79 & \\
\hline SCARED-P & & & & & & & & 0.01 \\
\hline $\mathrm{AO}$ & 12 & 16.00 & 14.07 & 18.04 & 4.68 & 8.86 & 27.22 & \\
\hline ABMT & 34 & 15.57 & 15.2 & 15.24 & 2.82 & 9.71 & 20.77 & \\
\hline SCARED-C & & & & & & & & 0.02 \\
\hline $\mathrm{AO}$ & 12 & 20.38 & 21.41 & 21.19 & 5.55 & 10.30 & 32.09 & \\
\hline ABMT & 34 & 17.45 & 15.38 & 16.33 & 3.38 & 9.67 & 22.99 & \\
\hline CIS-P & & & & & & & & 0.02 \\
\hline $\mathrm{AO}$ & 12 & 9.25 & 8.00 & 10.71 & 3.28 & 4.25 & 17.18 & \\
\hline ABMT & 34 & 11.58 & 9.97 & 11.42 & 1.83 & 7.80 & 15.04 & \\
\hline CIS-C & & & & & & & & 0.05 \\
\hline $\mathrm{AO}$ & 12 & 8.00 & 10.21 & 8.86 & 3.38 & 2.15 & 15.58 & \\
\hline ABMT & 34 & 5.66 & 6.19 & 5.15 & 1.62 & 1.97 & 8.33 & \\
\hline ACS-C & & & & & & & & 0.04 \\
\hline $\mathrm{AO}$ & 12 & 58.88 & 10.06 & 58.48 & 3.40 & 51.79 & 65.17 & \\
\hline ABMT & 34 & 52.62 & 9.06 & 54.53 & 2.25 & 50.07 & 58.98 & \\
\hline
\end{tabular}

Note: AOxABMT $=$ Comparison of assessed only and ABMT only groups. $N=$ number of participants, $M=$ Mean, $S D=$ Standard Deviation, $S E=$ Standard Error, $\mathrm{LB}=$ Lower bound for $95 \%$ confidence interval, $\mathrm{UB}=$ Upper bound of $95 \%$ confidence interval, Partial $\eta^{2}=$ Partial eta squared. 
Table 6. Comparison of outcomes on treatment targets at long-term follow-up between the ABMT only and $A B M T+C B T$ groups

\begin{tabular}{|c|c|c|c|c|c|c|c|c|}
\hline \multirow[b]{3}{*}{ Group } & \multirow[b]{3}{*}{$N$} & \multicolumn{3}{|c|}{ Unadjusted } & \multicolumn{3}{|c|}{ Adjusted } & \multirow[b]{3}{*}{$\begin{array}{c}\text { Partial } \\
\eta^{2}\end{array}$} \\
\hline & & & & & \multicolumn{3}{|c|}{$95 \% \mathrm{CI}$} & \\
\hline & & $M$ & $S D$ & $M$ & $S E$ & LB & UB & \\
\hline ABMTхCBT & & & & & & & & \\
\hline PARS & & & & & & & & 0.02 \\
\hline ABMT & 34 & 11.31 & 7.93 & 11.11 & 3.27 & 4.63 & 17.58 & \\
\hline CBT & 28 & 11.64 & 7.99 & 10.67 & 1.58 & 7.54 & 13.79 & \\
\hline SCARED-P & & & & & & & & 0.01 \\
\hline ABMT & 34 & 15.57 & 15.20 & 18.04 & 4.68 & 8.86 & 27.22 & \\
\hline CBT & 28 & 15.74 & 10.75 & 15.24 & 2.82 & 9.71 & 20.77 & \\
\hline SCARED-C & & & & & & & & 0.02 \\
\hline ABMT & 34 & 17.45 & 15.38 & 21.19 & 5.55 & 10.30 & 32.09 & \\
\hline CBT & 28 & 15.55 & 10.07 & 16.33 & 3.38 & 9.67 & 22.99 & \\
\hline CIS-P & & & & & & & & 0.02 \\
\hline ABMT & 34 & 11.58 & 9.97 & 10.71 & 3.28 & 4.25 & 17.18 & \\
\hline CBT & 28 & 8.21 & 8.07 & 11.42 & 1.83 & 7.80 & 15.04 & \\
\hline CIS-C & & & & & & & & 0.05 \\
\hline ABMT & 34 & 5.66 & 6.19 & 8.86 & 3.38 & 2.15 & 15.58 & \\
\hline CBT & 28 & 7.61 & 6.98 & 5.15 & 1.62 & 1.97 & 8.33 & \\
\hline ACS-C & & & & & & & & 0.04 \\
\hline ABMT & 34 & 52.62 & 9.06 & 58.48 & 3.40 & 51.79 & 65.17 & \\
\hline CBT & 28 & 54.05 & 6.64 & 54.53 & 2.25 & 50.07 & 58.98 & \\
\hline
\end{tabular}

Note: ABMTxCBT $=$ Comparison of ABMT only and ABMT+CBT groups. $N=$ number of participants, $M=$ Mean, $S D=$ Standard Deviation, $S E=$ Standard Error, $\mathrm{LB}=$ Lower bound for $95 \%$ confidence interval, $\mathrm{UB}=$ Upper bound of $95 \%$ confidence interval, Partial $\eta^{2}=$ Partial eta squared. 
Table 7. Comparison of outcomes on treatment targets at long-term follow-up between the $A B M T+C B T$ and assessed only groups

\begin{tabular}{|c|c|c|c|c|c|c|c|c|}
\hline \multirow[b]{3}{*}{ Group } & \multirow[b]{3}{*}{$N$} & \multicolumn{3}{|c|}{ Unadjusted } & \multicolumn{3}{|c|}{ Adjusted } & \multirow[b]{3}{*}{$\begin{array}{c}\text { Partial } \\
\eta^{2}\end{array}$} \\
\hline & & \multirow[b]{2}{*}{$M$} & \multirow[b]{2}{*}{$S D$} & \multirow[b]{2}{*}{$M$} & \multicolumn{3}{|c|}{$95 \% \mathrm{CI}$} & \\
\hline & & & & & $S E$ & LB & UB & \\
\hline CBTхAO & & & & & & & & \\
\hline PARS & & & & & & & & 0.02 \\
\hline CBT & 28 & 11.64 & 7.99 & 11.30 & 1.88 & 7.59 & 15.01 & \\
\hline $\mathrm{AO}$ & 12 & & & 9.73 & 3.04 & 3.74 & 15.71 & \\
\hline SCARED-P & & & & & & & & 0.01 \\
\hline CBT & 28 & 15.74 & 10.75 & 15.13 & 2.28 & 10.65 & 19.60 & \\
\hline $\mathrm{AO}$ & 12 & & & 16.08 & 3.51 & 9.21 & 22.96 & \\
\hline SCARED-C & & & & & & & & 0.03 \\
\hline CBT & 28 & 15.55 & 10.07 & 16.60 & 2.91 & 10.88 & 22.32 & \\
\hline $\mathrm{AO}$ & 12 & & & 21.53 & 4.69 & 12.30 & 30.77 & \\
\hline CIS-P & & & & & & & & 0.03 \\
\hline CBT & 28 & 8.21 & 8.07 & 7.65 & 1.58 & 4.55 & 10.74 & \\
\hline $\mathrm{AO}$ & 12 & & & 10.23 & 2.73 & 4.85 & 15.61 & \\
\hline CIS-C & & & & & & & & 0.02 \\
\hline CBT & 28 & 7.61 & 6.98 & 8.58 & 2.08 & 4.47 & 12.69 & \\
\hline $\mathrm{AO}$ & 12 & & & 7.77 & 3.69 & 0.44 & 15.10 & \\
\hline ACS-C & & & & & & & & 0.11 \\
\hline CBT & 28 & 54.05 & 6.64 & 53.20 & 1.74 & 49.79 & 56.61 & \\
\hline $\mathrm{AO}$ & 12 & & & 59.30 & 3.12 & 53.14 & 65.45 & \\
\hline
\end{tabular}


Table 8. Descriptive statistics for measures collected at long-term follow-up

\begin{tabular}{ccccc}
\hline Group & Min & Max & Mean & SD \\
\hline Assessed Only & & & & \\
PARS & 2 & 21 & 10.64 & 6.15 \\
SCARED-P & 0 & 40 & 16.00 & 14.07 \\
SCARED-C & 0 & 67 & 20.38 & 21.41 \\
CIS-P & 1 & 24 & 9.25 & 8.00 \\
CIS-C & 0 & 24 & 8.00 & 10.21 \\
ACS-C & 46 & 71 & 58.88 & 10.06 \\
ABMT only & & & & \\
PARS & 0 & 23 & 11.31 & 7.93 \\
SCARED-P & 0 & 54 & 15.57 & 15.20 \\
SCARED-C & 0 & 61 & 17.45 & 15.38 \\
CIS-P & 0 & 34 & 11.58 & 9.97 \\
CIS-C & 0 & 22 & 5.66 & 6.19 \\
ACS-C & 28 & 72 & 52.62 & 9.06 \\
ABMT and CBT & & & & \\
PARS & 0 & 23 & 11.64 & 7.99 \\
SCARED-P & 1 & 40 & 15.74 & 10.75 \\
SCARED-C & 3 & 38 & 15.55 & 10.07 \\
CIS-P & 0 & 31 & 8.21 & 8.07 \\
CIS-C & 0 & 20 & 7.61 & 6.98 \\
ACS-C & 44 & 69 & 54.05 & 6.64 \\
\hline
\end{tabular}

Note: $\mathrm{SD}=$ standard deviation. 
Figure 1. Single trial of the dot probe task

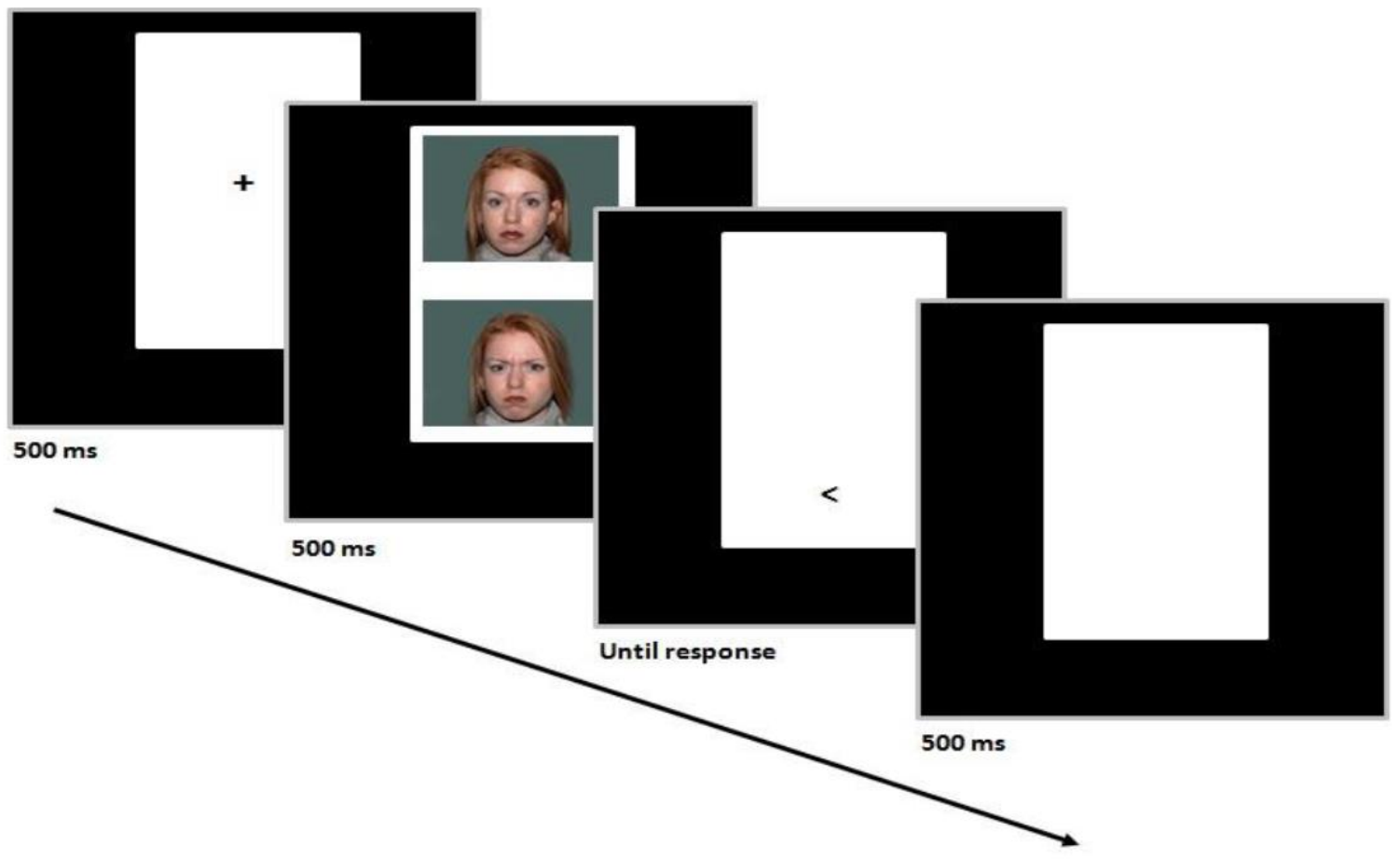


Figure 2. Eligible and participating youth

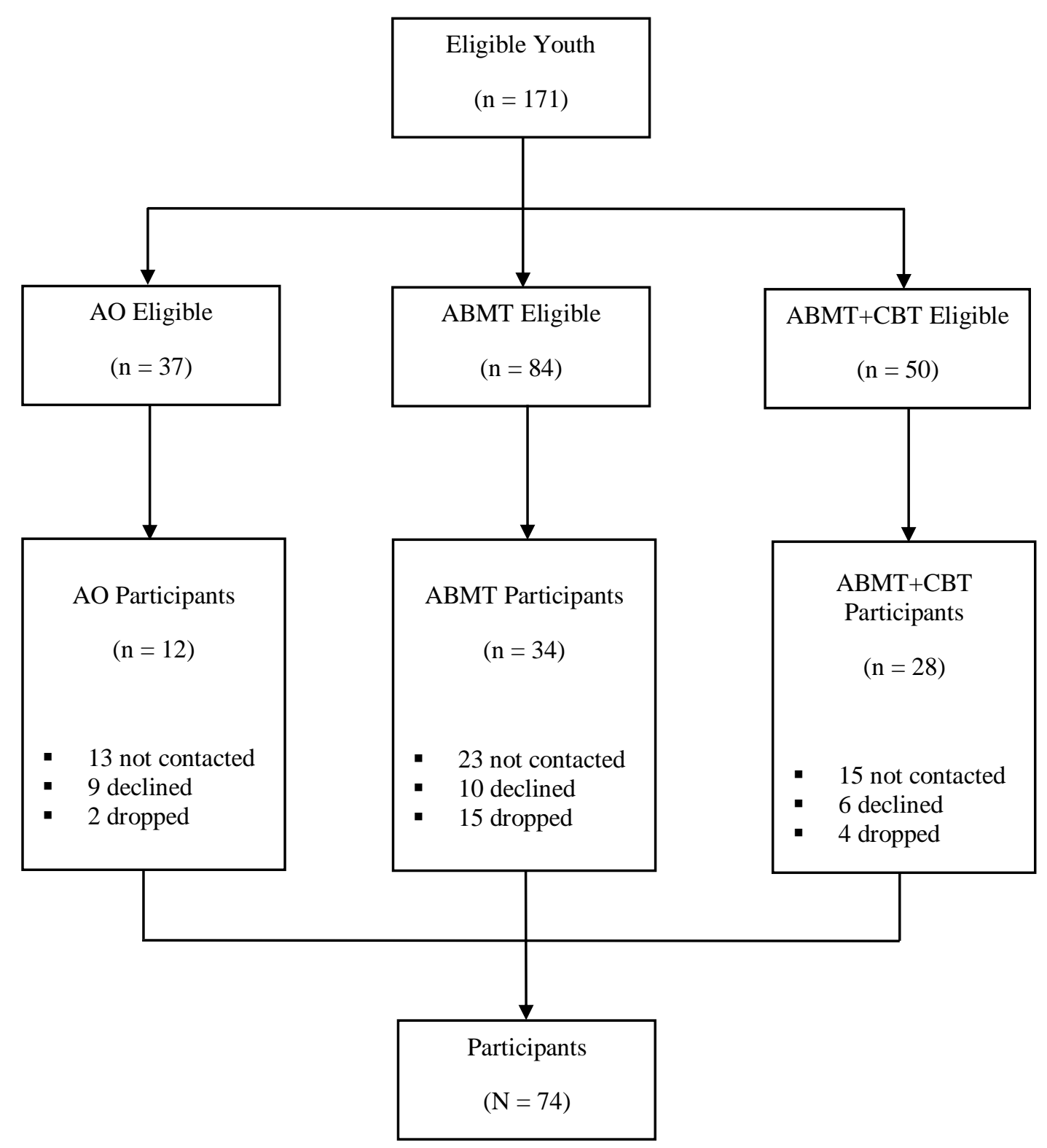




\section{FIELD STATEMENT}

Anxiety disorders in children and adolescents are associated with significant distress and impairment; further, the chronic nature of anxiety predicts impairment well into adulthood in most cases, indicating a need for early intervention among youth. Despite the presence of efficacious interventions such as CBT, barriers to treatment associated with cost of delivery and with availability of trained clinicians remain. The studies presented in this dissertation add to the literature on efforts to regulate the disparity between the demand and the availability of evidence-based interventions by capitalizing on the role of attentional processes in the maintenance and treatment of anxiety - specifically, expanding on recent work understanding $\mathrm{ABMT}$ as an alternative, cost-effective intervention with respect to administration and delivery. Findings provided in chapter two on the factor structure and concurrent validity of the Attentional Control Scale for Children support its potential as a brief, easily administered self-report questionnaire for measuring attentional control, which may be clinically useful in gauging treatment progress and outcomes as they relate to ABMT. Similarly, chapter three examined different indices generated by the dot probe task, a widespread tool used for quantifying and targeting threat-related attention bias, and identified attention bias variability as a reliable index for clinical use. The final study of this dissertation contributed to evidence for the utility of ABMT in treating anxiety, with findings indicating youth who completed $\mathrm{ABMT}$ as a stand-alone treatment four years prior 1) reported minimal anxiety symptoms and impairment and 2) did not significantly differ from youth who completed ABMT as an adjunctive treatment to CBT.

The present collection of studies seeks to prioritize the valid and reliable measurement of attentional processes in youth, and the development and refinement of cost-effective, evidence-based interventions targeting attentional processes relevant to anxiety disorders in youth. Designing innovative approaches may be key in reducing burden on providers and patients in order to improve access to care. Attention bias modification treatment is an example of exploring innovative new treatments, translating work grounded in cognitive neuroscience into a brief, portable, and low-cost intervention. Despite burgeoning research on ABMT over the past few decades, questions remain regarding its efficacy and position relative to other mainstream interventions for anxiety. Findings from the present dissertation speak 
to its promising clinical utility in youth and aim to propel the field forward in further examining its potential as a gold standard intervention. 


\section{REFERENCES}

Abend, R., Pine, D., \& Bar-Haim, Y. (2014). The TAU-NIMH attention bias measurement toolbox.

Amir, N., Beard, C., Burns, M., \& Bomyea, J. (2009). Attention modification program in individuals with generalized anxiety disorder. Journal of Abnormal Psychology, 118(1), 28-33. doi:2009-01738016 [pii]

Amir, N., Beard, C., Taylor, C. T., Klumpp, H., Elias, J., Burns, M., \& Chen, X. (2009). Attention training in individuals with generalized social phobia: A randomized controlled trial. Journal of Consulting and Clinical Psychology, 77(5), 961-973. doi:2009-17643-016 [pii]

Amir, N., Taylor, C. T., \& Donohue, M. C. (2011). Predictors of response to an attention modification program in generalized social phobia. Journal of Consulting and Clinical Psychology, 79(4), 533.

Bar-Haim, Y. (2010). Research review: Attention bias modification (ABM): a novel treatment for anxiety disorders. Journal of Child Psychology and Psychiatry, 51(8), 859-870.

Bar-Haim, Y., Lamy, D., Pergamin, L., Bakermans-Kranenburg, M. J., \& Van, I. M. H. (2007). Threatrelated attentional bias in anxious and nonanxious individuals: a meta-analytic study. Psychological Bulletin, 133(1), 1-24. doi:10.1037/0033-2909.133.1.1

Bar-Haim, Y., Morag, I., \& Glickman, S. (2011). Training anxious children to disengage attention from threat: a randomized controlled trial. Journal of Child Psychology and Psychiatry, 52(8), 861-869.

Bebbington, P., Brugha, T., Meltzer, H., Jenkins, R., Ceresa, C., Farrell, M., \& Lewis, G. (2000). Neurotic disorders and the receipt of psychiatric treatment. Psychological Medicine, 30(06), 1369-1376.

Bechor, M., Melendez, R., Rey, Y., Pettit, J.W., \& Silverman, W.K. (2015). Attentional Control Partially Explains the Association between Anxiety Symptoms and Depressive Symptoms among Clinic Referred Youth. Manuscript submitted for publication.

Bird, H. R., Andrews, H., Schwab-Stone, M., Goodman, S., Dulcan, M., Richters, J., . . Hoven, C. (1996). Global measures of impairment for epidemiologic and clinical use with children and adolescents. International Journal of Methods in Psychiatric Research. 
Bird, H. R., Shaffer, D., Fisher, P., \& Gould, M. S. (1993). The Columbia Impairment Scale (CIS): Pilot findings on a measure of global impairment for children and adolescents. International Journal of Methods in Psychiatric Research.

Birmaher, B., Brent, D. A., Chiappetta, L., Bridge, J., Monga, S., \& Baugher, M. (1999). Psychometric properties of the Screen for Child Anxiety Related Emotional Disorders (SCARED): a replication study. Journal of the American Academy of Child and Adolescent Psychiatry, 38(10), 1230-1236.

Birmaher, B., Khetarpal, S., Brent, D., Cully, M., Balach, L., Kaufman, J., \& Neer, S. M. (1997). The screen for child anxiety related emotional disorders (SCARED): Scale construction and psychometric characteristics. Journal of the American Academy of Child and Adolescent Psychiatry, 36(4), 545-553.

Bower, P., \& Gilbody, S. (2005). Stepped care in psychological therapies: access, effectiveness and efficiency Narrative literature review. The British Journal of Psychiatry, 186(1), 11-17.

Bradley, B. P., Mogg, K., Falla, S. J., \& Hamilton, L. R. (1998). Attentional bias for threatening facial expressions in anxiety: Manipulation of stimulus duration. Cognition and Emotion, 12(6), 737753.

Bradley, B. P., Mogg, K., White, J., Groom, C., \& Bono, J. (1999). Attentional bias for emotional faces in generalized anxiety disorder. British Journal of Clinical Psychology, 38(3), 267-278.

Breslin, F. C., Sobell, M. B., Sobell, L. C., Buchan, G., \& Cunningham, J. A. (1997). Toward a stepped care approach to treating problem drinkers: the predictive utility of within-treatment variables and therapist prognostic ratings. Addiction, 92(11), 1479-1489.

Britton, J. C., Suway, J. G., Clementi, M. A., Fox, N. A., Pine, D. S., \& Bar-Haim, Y. (2014). Neural changes with attention bias modification for anxiety: a randomized trial. Social Cognitive and Affective Neuroscience. doi:nsu141 [pii]

Brooks, S. J., \& Kutcher, S. (2001). Diagnosis and measurement of adolescent depression: A review of commonly utilized instruments. Journal of Child and Adolescent Psychopharmacology, 11(4), 341-376. 
Brown, H. M., Eley, T. C., Broeren, S., Macleod, C., Rinck, M., Hadwin, J. A., \& Lester, K. J. (2014). Psychometric properties of reaction time based experimental paradigms measuring anxiety-related information-processing biases in children. Journal of Anxiety Disorders, 28(1), 97-107. doi:10.1016/j.janxdis.2013.11.004

Browning, M., Holmes, E. A., Murphy, S. E., Goodwin, G. M., \& Harmer, C. J. (2010). Lateral prefrontal cortex mediates the cognitive modification of attentional bias. Biological Psychiatry, 67(10), 919925.

Chen, N. T., Clarke, P. J., Watson, T. L., MacLeod, C., \& Guastella, A. J. (2015). Attentional bias modification facilitates attentional control mechanisms: evidence from eye tracking. Biological Psychology, 104, 139-146. doi:10.1016/j.biopsycho.2014.12.002

Cisler, J. M., \& Koster, E. H. (2010). Mechanisms of attentional biases towards threat in anxiety disorders: An integrative review. Clinical Psychology Review, 30(2), 203-216.

Clark, D. A., \& Beck, A. T. (2010). Cognitive theory and therapy of anxiety and depression: convergence with neurobiological findings. Trends in Cognitive Sciences, 14(9), 418-424.

Clarke, P. J., Notebaert, L., \& MacLeod, C. (2014). Absence of evidence or evidence of absence: reflecting on therapeutic implementations of attentional bias modification. BMC Psychiatry, 14, 8. doi:10.1186/1471-244X-14-8

Cooper, R. M., Bailey, J. E., Diaper, A., Stirland, R., Renton, L. E., Benton, C. P., . . Munafo, M. R. (2011). Effects of $7.5 \% \mathrm{CO}(2)$ inhalation on allocation of spatial attention to facial cues of emotional expression. Cognition \& Emotion, 25(4), 626-638. doi:10.1080/02699931.2010.508887

Costello, A. B., \& Osborne, J. W. (2005). Best practices in exploratory factor analysis: Four recommendations for getting the most from your analysis. Practical Assessment, Research, and Evaluation, 10(7), 1-9. http://pareonline. net/getvn. asp

Costello, E. J., Egger, H. L., Angold, A. J. C., \& Clinics, A. P. (2005). The developmental epidemiology of anxiety disorders: phenomenology, prevalence, and comorbidity. Child and Adolescent Psychiatric Clinics of North America, 14(4), 631-648. 
Dadds, M. R., Holland, D. E., Laurens, K. R., Mullins, M., Barrett, P. M., \& Spence, S. H. (1999). Early intervention and prevention of anxiety disorders in children: Results at 2-year follow-up. Journal of Consulting and Clinical Psychology, 67(1), 145.Davis, M., \& Whalen, P. J. (2001). The amygdala: vigilance and emotion. Molecular Psychiatry, 6(1), 13-34.

Dekovic, M., Buist, K., \& Reitz, E. (2004). Stability and changes in problem behavior during adolescence: Latent growth analysis. Journal of Youth and Adolescence, 33, 1-12.

Derakshan, N., \& Eysenck, M. W. (2009). Anxiety, processing efficiency, and cognitive performance: New developments from attentional control theory. European Psychologist, 14(2), 168-176.

Derryberry, D., \& Reed, M. A. (2002). Anxiety-related attentional biases and their regulation by attentional control. Journal of Abnormal Psychology, 111(2), 225-236. doi:10.1037/0021-843x.111.2.225

Dudeney, J., Sharpe, L., \& Hunt, C. (2015). Attentional bias towards threatening stimuli in children with anxiety: A meta-analysis. Clinical Psychology Review, 40, 66-75.

Eldar, S., Apter, A., Lotan, D., Edgar, K. P., Naim, R., Fox, N. A., . . Bar-Haim, Y. (2012). Attention bias modification treatment for pediatric anxiety disorders: a randomized controlled trial. American Journal of Psychiatry, 169(2), 213-220.

Enders, C., Keller, B., \& Levy, R. (2017). A chained equations imputation approach for multilevel data with categorical and continuous variables. Psychological Methods, Advance online publication. doi. org/10.1037/met0000148.

Enock, P. M., Hofmann, S. G., \& McNally, R. J. (2014). Attention Bias Modification Training Via Smartphone to Reduce Social Anxiety: A Randomized, Controlled Multi-Session Experiment. Cognitive Therapy and Research, 38(2), 200-216. doi:10.1007/s10608-014-9606-z

Essau, C. A., Conradt, J., \& Petermann, F. (2002). Course and outcome of anxiety disorders in adolescents. Journal of Anxiety Disorders, 16(1), 67-81.

Eysenck, M. W., \& Derakshan, N. (2011). New perspectives in attentional control theory. Personality and Individual Differences, 50(7), 955-960.

Eysenck, M. W., Derakshan, N., Santos, R., \& Calvo, M. G. (2007). Anxiety and cognitive performance: attentional control theory. Emotion, 7(2), 336-353. doi:10.1037/1528-3542.7.2.336 
Fabrigar, L. R., Wegener, D. T., MacCallum, R. C., \& Strahan, E. J. (1999). Evaluating the use of exploratory factor analysis in psychological research. Psychological Methods, 4(3), 272-299.

Field, A. P., Hadwin, J. A., \& Lester, K. J. (2011). Information processing biases in child and adolescent anxiety: A developmental perspective. Anxiety Disorders in Children and Adolescents, 103-128.

Floyd, F. J., \& Widaman, K. F. (1995). Factor analysis in the development and refinement of clinical assessment instruments. Psychological Assessment, 7, 286-299.

Graham, J. W. (2009). Missing data analysis: Making it work in the real world. Annual Review of Psychology, 60, 549-576.

Hakamata, Y., Lissek, S., Bar-Haim, Y., Britton, J. C., Fox, N. A., Leibenluft, E., . . Pine, D. S. (2010). Attention bias modification treatment: a meta-analysis toward the establishment of novel treatment for anxiety. Biological Psychiatry, 68(11), 982-990. doi:10.1016/j.biopsych.2010.07.021

Hariri, A. R., Mattay, V. S., Tessitore, A., Fera, F., \& Weinberger, D. R. (2003). Neocortical modulation of the amygdala response to fearful stimuli. Biological Psychiatry, 53(6), 494-501.

Heeren, A., De Raedt, R., Koster, E. H., \& Philippot, P. (2013). The (neuro)cognitive mechanisms behind attention bias modification in anxiety: proposals based on theoretical accounts of attentional bias. Frontiers in Human Neuroscience, 7, 119. doi:10.3389/fnhum.2013.00119

Heeren, A., Mogoase, C., McNally, R. J., Schmitz, A., \& Philippot, P. (2015). Does attention bias modification improve attentional control? A double-blind randomized experiment with individuals with social anxiety disorder. Journal of Anxiety Disorders, 29, 35-42. doi:10.1016/j.janxdis.2014.10.007

Heim-Dreger, U., Kohlmann, C.-W., Eschenbeck, H., \& Burkhardt, U. (2006). Attentional biases for threatening faces in children: vigilant and avoidant processes. Emotion, 6(2), 320.

Iacoviello, B. M., Wu, G., Abend, R., Murrough, J. W., Feder, A., Fruchter, E., . . Charney, D. S. (2014). Attention bias variability and symptoms of posttraumatic stress disorder. Journal of Traumatic Stress, 27(2), 232-239. doi:10.1002/jts.21899 
Jaccard, J., \& Guilamo-Ramos, V. (2002). Analysis of variance frameworks in clinical child and adolescent psychology: Issues and recommendations. Journal of Clinical Child and Adolescent Psychology, 31(1), 130-146.

Judah, M. R., Grant, D. M., Mills, A. C., \& Lechner, W. V. (2014). Factor structure and validation of the attentional control scale. Cognition and Emotion, 28(3), 433-451.

Kazdin, A. E., \& Blase, S. L. (2011). Rebooting psychotherapy research and practice to reduce the burden of mental illness. Perspectives on Psychological Science, 6(1), 21-37.

Keller, B., \& Enders, C. (2017). Blimp user's manual (Version 1.0). Los Angeles, CA.

Keller, M. B., Lavori, P. W., Wunder, J., Beardslee, W. R., Schwartz, C. E., \& Roth, J. (1992). Chronic course of anxiety disorders in children and adolescents. Journal of the American Academy of Child and Adolescent Psychiatry, 31(4), 595-599.

Kendall, P. C. (1994). Treating anxiety disorders in children: Results of a randomized clinical trial. Journal of Consulting and Clinical Psychology, 62(1), 100-110.

Klein, D. N., Dougherty, L. R., \& Olino, T. M. (2005). Toward guidelines for evidence-based assessment of depression in children and adolescents. Journal of Clinical Child and Adolescent Psychology, 34(3), 412-432. doi:10.1207/s15374424jccp3403_3

Klumpp, H., \& Amir, N. (2010). Preliminary Study of Attention Training to Threat and Neutral Faces on Anxious Reactivity to a Social Stressor in Social Anxiety. Cognitive Therapy and Research, 34(3), 263-271.

Kolko, D. J., Brent, D. A., Baugher, M., Bridge, J., \& Birmaher, B. (2000). Cognitive and family therapies for adolescent depression: treatment specificity, mediation, and moderation. Journal of Consulting and Clinical Psychology, 68(4), 603-614.

Kovacs, M. (1985). The Children's Depression Inventory (CDI). Psychopharmacology Bulletin, 21(4), 995-998.

Kuckertz, J. M., \& Amir, N. (2015). Attention bias modification for anxiety and phobias: current status and future directions. Curr Psychiatry Rep, 17(2), 9. doi:10.1007/s11920-014-0545-x 
Kuckertz, J. M., Gildebrant, E., Liliequist, B., Karlstrom, P., Vappling, C., Bodlund, O., . . Carlbring, P. (2014). Moderation and mediation of the effect of attention training in social anxiety disorder. Behav Res Ther, 53, 30-40. doi:10.1016/j.brat.2013.12.003

Ledoux, J. (1996). The Emotional Brain. New York: Touchstone.,() Lehrer, J.(2007) Proust was a neuroscientist. In: New York: Houghton Mifflin.

Legerstee, J. S., Tulen, J. H., Kallen, V. L., Dieleman, G. C., Treffers, P. D., Verhulst, F. C., \& Utens, E. M. (2009). Threat-related selective attention predicts treatment success in childhood anxiety disorders. Journal of the American Academy of Child and Adolescent Psychiatry, 48(2), 196-205.

Lonigan, C. J., \& Vasey, M. W. (2009). Negative affectivity, effortful control, and attention to threatrelevant stimuli. Journal of Abnormal Child Psychology, 37(3), 387-399.

Lonigan, C. J., Vasey, M. W., Phillips, B. M., \& Hazen, R. A. (2004). Temperament, anxiety, and the processing of threat-relevant stimuli. Journal of Clinical Child and Adolescent Psychology, 33(1), 8-20.

Lovell, K., \& Richards, D. (2000). Multiple access points and levels of entry (MAPLE): ensuring choice, accessibility and equity for CBT services. Behavioural and Cognitive Psychotherapy, 28(04), 379391.

Lowther, H., \& Newman, E. (2014). Attention bias modification (ABM) as a treatment for child and adolescent anxiety: a systematic review. Journal of Affective Disorders, 168, 125-135. doi:10.1016/j.jad.2014.06.051

Lyneham, H. J., Abbott, M. J., \& Rapee, R. M. (2007). Interrater reliability of the Anxiety Disorders Interview Schedule for DSM-IV: child and parent version. Journal of the American Academy of Child and Adolescent Psychiatry, 46(6), 731-736. doi:10.1097/chi.0b013e3180465a09

Macleod, C., \& Clarke, P. J. F. (2015). The attentional bias modification approach to anxiety intervention. Clinical Psychological Science, 3(1), 58-78. doi:10.1177/2167702614560749

MacLeod, C., Mathews, A., \& Tata, P. (1986). Attentional bias in emotional disorders. Journal of Abnormal Psychology, 95(1), 15. 
MacNamara, A., Kappenman, E. S., Black, S. R., Bress, J. N., \& Hajcak, G. (2012). 11 Integrating Behavioral and Electrocortical Measures of Attentional Bias Toward Threat. Handbook of selfregulatory processes in development: New directions and international perspectives, 215.

Mathews, A., \& MacLeod, C. (1994). Cognitive approaches to emotion and emotional disorders. Annual Review of Psychology, 45, 25.

Mathews, A., \& MacLeod, C. (2002). Induced processing biases have causal effects on anxiety. Cognition and Emotion, 16(3), 331-354.

McNally, R. J., Enock, P. M., Tsai, C., \& Tousian, M. (2013). Attention bias modification for reducing speech anxiety. Behaviour Research and Therapy, 51(12), 882-888. doi:10.1016/j.brat.2013.10.001

Melendez, R., Bechor, M., Rey, Y., Pettit, J. W., \& Silverman, W. K. (2017). Attentional control scale for children: Factor structure and concurrent validity among children and adolescents referred for anxiety disorders. Journal of Clinical Psychology, 73(4), 489-499.

Mogg, K., \& Bradley, B. P. (1999). Some methodological issues in assessing attentional biases for threatening faces in anxiety: A replication study using a modified version of the probe detection task. Behaviour Research and Therapy, 37(6), 595-604.

Mogg, K., \& Bradley, B. P. (2002). Selective orienting of attention to masked threat faces in social anxiety. Behaviour Research and Therapy, 40(12), 1403-1414.

Mogg, K., \& Bradley, B. P. (2006). Time course of attentional bias for fear-relevant pictures in spiderfearful individuals. Behaviour Research and Therapy, 44(9), 1241-1250.

doi:10.1016/j.brat.2006.05.003

Mogg, K., Philippot, P., \& Bradley, B. P. (2004). Selective attention to angry faces in clinical social phobia. Journal of Abnormal Psychology, 113(1), 160-165. doi:10.1037/0021-843X.113.1.160

Mogoase, C., David, D., \& Koster, E. H. (2014). Clinical efficacy of attentional bias modification procedures: an updated meta-analysis. Journal of Clinical Psychology, 70(12), 1133-1157. doi:10.1002/jclp.22081 
Monga, S., Birmaher, B., Chiappetta, L., Brent, D., Kaufman, J., Bridge, J., \& Cully, M. (2000). Screen for child anxiety-related emotional disorders (SCARED): Convergent and divergent validity. Depression and Anxiety, 12(2), 85-91.

Monk, C. S., Nelson, E. E., McClure, E. B., Mogg, K., Bradley, B. P., Leibenluft, E., . . Ernst, M. (2006). Ventrolateral prefrontal cortex activation and attentional bias in response to angry faces in adolescents with generalized anxiety disorder. American Journal of Psychiatry, 163(6), 10911097.

Monk, C. S., Telzer, E. H., Mogg, K., Bradley, B. P., Mai, X., Louro, H. M., . . Pine, D. S. (2008). Amygdala and ventrolateral prefrontal cortex activation to masked angry faces in children and adolescents with generalized anxiety disorder. Archives of General Psychiatry, 65(5), 568-576.

Muris, P., \& Ollendick, T. H. (2005). The role of temperament in the etiology of child psychopathology. Clinical Child and Family Psychology Review, 8(4), 271-289.

Muris, P., de Jong, P. J., \& Engelen, S. (2004). Relationships between neuroticism, attentional control, and anxiety disorders symptoms in non-clinical children. Personality and Individual Differences, 37(4), 789-797. doi:10.1016/j.paid.2003.10.007

Muris, P., Mayer, B., Lint, C. v., \& Hofman, S. (2008). Attentional control and psychopathological symptoms in children. Personality and Individual Differences, 44(7), 1495-1505. doi:10.1016/j.paid.2008.01.006

Muris, P., Meesters, C., \& Rompelberg, L. (2007). Attention control in middle childhood: Relations to psychopathological symptoms and threat perception distortions. Behaviour Research and Therapy, 45(5), 997-1010.

Naim, R., Abend, R., Wald, I., Eldar, S., Levi, O., Fruchter, E., ... \& Bliese, P. D. (2015). Threat-related attention bias variability and posttraumatic stress. American Journal of Psychiatry, 172(12), 12421250.

Nigg, J. T. (2006). Temperament and developmental psychopathology. Journal of Child Psychology and Psychiatry, 47(3-4), 395-422. 
Nomura, M., Ohira, H., Haneda, K., Iidaka, T., Sadato, N., Okada, T., \& Yonekura, Y. (2004). Functional association of the amygdala and ventral prefrontal cortex during cognitive evaluation of facial expressions primed by masked angry faces: an event-related fMRI study. Neuroimage, 21(1), 352363.

Ólafsson, R. P., Smári, J., Guðmundsdóttir, F., Olafsdóttir, G., Harðardóttir, H. L., \& Einarsson, S. M. (2011). Self reported attentional control with the Attentional Control Scale: Factor structure and relationship with symptoms of anxiety and depression. Journal of Anxiety Disorders, 25(6), 777 782.

Ollendick, T. H. (1983). Reliability and validity of the revised fear survey schedule for children (FSSCR). Behaviour Research and Therapy, 21(6), 685-692.

Ollendick, T. H., White, S. W., Richey, J., Kim-Spoon, J., Ryan, S. M., Wieckowski, A. T., ... \& Smith, M. (2019). Attention bias modification treatment for adolescents with social anxiety disorder. Behavior therapy, 50(1), 126-139.

Pela, O. A., \& Reynolds, C. R. (1982). Cross-cultural application of the Revised-Children's Manifest Anxiety Scale: normative and reliability data for Nigerian primary school children. Psychological Reports, 51(3f), 1135-1138.

Pergamin-Hight, L., Pine, D. S., Fox, N. A., \& Bar-Haim, Y. (2016). Attention bias modification for youth with social anxiety disorder. Journal of Child Psychology and Psychiatry, 57(11), 1317-1325.

Pettit, J. W., Bechor, M., Rey, Y., Vasey, M. W., Abend, R., Pine, D. S., Bar-Haim, Y., Jaccard, J., Silverman, W. K. (2019). A randomized controlled trial of attention bias modification treatment in youth with treatment-resistant anxiety disorders. Journal of the American Academy of Child and Adolescent Psychiatry. doi.org/10.1016/j.jaac.2019.02.018

Pine, D. S. (2009). Integrating research on development and fear learning: a vision for clinical neuroscience? Depression and Anxiety, 26(9), 775-779.

Price, M., Tone, E. B., \& Anderson, P. L. (2011). Vigilant and avoidant attention biases as predictors of response to cognitive behavioral therapy for social phobia. Depression and Anxiety, 28(4), 349353. 
Price, R. B., Kuckertz, J. M., Siegle, G. J., Ladouceur, C. D., Silk, J. S., Ryan, N. D., . . Amir, N. (2015). Empirical recommendations for improving the stability of the dot-probe task in clinical research. Psychological Assessment, 27(2), 365-376. doi:10.1037/pas0000036

Price, R. B., Wallace, M., Kuckertz, J. M., Amir, N., Graur, S., Cummings, L., ... \& Bar-Haim, Y. (2016). Pooled patient-level meta-analysis of children and adults completing a computer-based anxiety intervention targeting attentional bias. Clinical Psychology review, 50, 37-49.

Puliafico, A. C., \& Kendall, P. C. (2006). Threat-related attentional bias in anxious youth: A review. Clinical Child and Family Psychology Review, 9(3-4), 162-180.

Reynolds, C. R., \& Richmond, B. O. (1978). What I think and feel: A revised measure of children's manifest anxiety. Journal of Abnormal Child Psychology, 6(2), 271-280.

Riemann, B. C., Kuckertz, J. M., Rozenman, M., Weersing, V. R., \& Amir, N. (2013). Augmentation of youth cognitive behavioral and pharmacological interventions with attention modification: a preliminary investigation. Depression and Anxiety, 30(9), 822-828. doi:10.1002/da.22127

Roy, A. K., Dennis, T. A., \& Warner, C. M. (2015). A Critical Review of Attentional Threat Bias and Its Role in the Treatment of Pediatric Anxiety Disorders. Journal of Cognitive Psychotherapy, 29(3), 171-184. doi:10.1891/0889-8391.29.3.171

Rozenman, M., Weersing, V. R., \& Amir, N. (2011). A case series of attention modification in clinically anxious youths. Behaviour Research and Therapy, 49(5), 324-330.

Research Units on Pediatric Psychopharmacology Anxiety Study Group. (2002). The pediatric anxiety rating scale (PARS): Development and psychometric properties. Journal of the American Academy of Child \& Adolescent Psychiatry, 41(9), 1061-1069.

Saavedra, L. M., Silverman, W. K., Morgan-Lopez, A. A., \& Kurtines, W. M. (2010). Cognitive behavioral treatment for childhood anxiety disorders: long-term effects on anxiety and secondary disorders in young adulthood. Journal of Child Psychology and Psychiatry, 51(8), 924-934.

Schmukle, S. C. (2005). Unreliability of the dot probe task. European Journal of Personality, 19(7), 595605. doi:10.1002/per.554 
Shain, B. N., Naylor, M., \& Alessi, N. (1990). Comparison of self-rated and clinician-rated measures of depression in adolescents. The American Journal of Psychiatry, 147(6), 793-795.

Shechner, T., Rimon-Chakir, A., Britton, J. C., Lotan, D., Apter, A., Bliese, P. D., . . Bar-Haim, Y. (2014). Attention bias modification treatment augmenting effects on cognitive behavioral therapy in children with anxiety: randomized controlled trial. Journal of the American Academy of Child and Adolescent Psychiatry, 53(1), 61-71. doi:10.1016/j.jaac.2013.09.016

Shechner, T., Rimon-Chakir, A., Britton, J. C., Lotan, D., Apter, A., Bliese, P. D., . . Psychiatry, A. (2014). Attention bias modification treatment augmenting effects on cognitive behavioral therapy in children with anxiety: randomized controlled trial. 53(1), 61-71.

Silverman, W. K., \& Albano, A. M. (1996). Anxiety Disorders Interview Schedule for Children-IV (child and parent versions). San Antonio. TX: Psychological Corporation.

Silverman, W. K., \& Albano, A. M. (1996). Anxiety Disorders Interview Schedule for DSM-IV.: Parent interview schedule (Vol. 1): Oxford University Press.

Silverman, W. K., \& Field, A. P. (2011). Anxiety disorders in children and adolescents: Cambridge University Press.

Silverman, W. K., \& Ollendick, T. H. (2005). Evidence-based assessment of anxiety and its disorders in children and adolescents. Journal of Clinical Child and Adolescent Psychology, 34(3), 380-411.

Silverman, W. K., Kurtines, W. M., Ginsburg, G. S., Weems, C. F., Lumpkin, P. W., \& Carmichael, D. H. (1999). Treating anxiety disorders in children with group cognitive-behavioral therapy: A randomized clinical trial. Journal of Consulting and Clinical Psychology, 67(6), 995-1003.

Silverman, W. K., Kurtines, W. M., Jaccard, J., \& Pina, A. A. (2009). Directionality of change in youth anxiety treatment involving parents: An initial examination. Journal of Consulting and Clinical Psychology, 77(3), 474-485. doi:10.1037/a0015761

Silverman, W. K., Saavedra, L. M., \& Pina, A. A. (2001). Test-retest reliability of anxiety symptoms and diagnoses with the Anxiety Disorders Interview Schedule for DSM-IV: child and parent versions. Journal of the American Academy of Child and Adolescent Psychiatry, 40(8), 937-944. 
Southam-Gerow, M. A., \& Kendall, P. C. (2000). Cognitive-behaviour therapy with youth: advances, challenges, and future directions. Clinical Psychology \& Psychotherapy, 7(5), 343-366.

Spence, S. H., Donovan, C. L., March, S., Gamble, A., Anderson, R. E., Prosser, S., \& Kenardy, J. (2011). A randomized controlled trial of online versus clinic-based CBT for adolescent anxiety. Journal of Consulting and Clinical Psychology, 79(5), 629.

Sposari, J. A., \& Rapee, R. M. (2007). Attentional bias toward facial stimuli under conditions of social threat in socially phobic and nonclinical participants. Cognitive Therapy and Research, 31(1), 2337.

Staugaard, S. R. (2009). Reliability of two versions of the dot-probe task using photographic faces. Psychology Science Quarterly, 51(3), 339-350.

Sterba, S. K., Prinstein, M. J., \& Cox, M. J. (2007). Trajectories of internalizing problems across childhood: Heterogeneity, external validity, and gender differences. Development and Psychopathology, 19(2), 345-366.

Storch, E. A., Caporino, N. E., Morgan, J. R., Lewin, A. B., Rojas, A., Brauer, L., . . Murphy, T. K. (2011). Preliminary investigation of web-camera delivered cognitive-behavioral therapy for youth with obsessive-compulsive disorder. Psychiatry Research, 189(3), 407-412.

Susa, G., Pitica, I., Benga, O., \& Miclea, M. (2012). The self regulatory effect of attentional control in modulating the relationship between attentional biases toward threat and anxiety symptoms in children. Cognition and Emotion, 26(6), 1069-1083. doi:10.1080/02699931.2011.638910

Taylor, C. T., Aupperle, R. L., Flagan, T., Simmons, A. N., Amir, N., Stein, M. B., \& Paulus, M. P. (2014). Neural correlates of a computerized attention modification program in anxious subjects. Social Cognitive and Affective Neuroscience, 9(9), 1379-1387. doi:10.1093/scan/nst128

Telzer, E. H., Mogg, K., Bradley, B. P., Mai, X., Ernst, M., Pine, D. S., \& Monk, C. S. (2008). Relationship between trait anxiety, prefrontal cortex, and attention bias to angry faces in children and adolescents. Biological Psychology, 79(2), 216-222. 
Tottenham, N., Tanaka, J. W., Leon, A. C., McCarry, T., Nurse, M., Hare, T. A., .. Nelson, C. (2009). The NimStim set of facial expressions: judgments from untrained research participants. Psychiatry Research, 168(3), 242-249.

Van Bockstaele, B., Verschuere, B., Tibboel, H., De Houwer, J., Crombez, G., \& Koster, E. H. (2014). A review of current evidence for the causal impact of attentional bias on fear and anxiety. Psychological Bulletin, 140(3), 682-721. doi:10.1037/a0034834

Vasey, M. W., Daleiden, E. L., Williams, L. L., \& Brown, L. M. (1995). Biased attention in childhood anxiety disorders: A preliminary study. Journal of Abnormal Child Psychology, 23(2), 267-279.

Vasey, M. W., El-Hag, N., \& Daleiden, E. L. (1996). Anxiety and the Processing of Emotionally Threatening Stimuli: Distinctive Patterns of Selective Attention among High-and Low-TestAnxious Children. Child Development, 67(3), 1173-1185.

Verstraeten, K., Vasey, M. W., Claes, L., \& Bijttebier, P. (2010). The assessment of effortful control in childhood: Questionnaires and the Test of Everyday Attention for Children compared. Personality and Individual Differences, 48(1), 59-65.

Vos, T., Haby, M. M., Magnus, A., Mihalopoulos, C., Andrews, G., \& Carter, R. (2005). Assessing costeffectiveness in mental health: helping policy-makers prioritize and plan health services. Australian and New Zealand Journal of Psychiatry, 39(8), 701-712.

Waechter, S., \& Stolz, J. A. (2015). Trait Anxiety, State Anxiety, and Attentional Bias to Threat: Assessing the Psychometric Properties of Response Time Measures. Cognitive Therapy and Research, 39(4), 441-458. doi:10.1007/s10608-015-9670-z

Waechter, S., Nelson, A. L., Wright, C., Hyatt, A., \& Oakman, J. (2013). Measuring Attentional Bias to Threat: Reliability of Dot Probe and Eye Movement Indices. Cognitive Therapy and Research, 38(3), 313-333. doi:10.1007/s10608-013-9588-2

Walkup, J. T., Albano, A. M., Piacentini, J., Birmaher, B., Compton, S. N., Sherrill, J. T., ... \& Iyengar, S. (2008). Cognitive behavioral therapy, sertraline, or a combination in childhood anxiety. New England Journal of Medicine, 359(26), 2753-2766. 
Wass, S., Porayska-Pomsta, K., \& Johnson, M. H. (2011). Training attentional control in infancy. Current Biology, 21(18), 1543-1547.

Waters, A. M., Henry, J., Mogg, K., Bradley, B. P., \& Pine, D. S. (2010). Attentional bias towards angry faces in childhood anxiety disorders. Journal of Behavior Therapy and Experimental Psychiatry, 41(2), 158-164.

Waters, A. M., Mogg, K., \& Bradley, B. P. (2012). Direction of threat attention bias predicts treatment outcome in anxious children receiving cognitive-behavioural therapy. Behaviour Research and Therapy, 50(6), 428-434.

Waters, A. M., Mogg, K., Bradley, B. P., \& Pine, D. S. (2008). Attentional bias for emotional faces in children with generalized anxiety disorder. Journal of the American Academy of Child and Adolescent Psychiatry, 47(4), 435-442. doi:10.1097/CHI.0b013e3181642992

Weisz, J. R. (2000). Agenda for child and adolescent psychotherapy research: On the need to put science into practice. Archives of General Psychiatry, 57(9), 837-838.

White, L. K., Sequeira, S., Britton, J. C., Brotman, M. A., Gold, A. L., Berman, E., ... \& Leibenluft, E. (2017). Complementary features of attention bias modification therapy and cognitive-behavioral therapy in pediatric anxiety disorders. American Journal of Psychiatry, 174(8), 775-784.

Wood, J. J., Piacentini, J. C., Bergman, R. L., McCracken, J., \& Barrios, V. (2002). Concurrent validity of the anxiety disorders section of the anxiety disorders interview schedule for DSM-IV: child and parent versions. Journal of Clinical Child and Adolescent Psychology, 31(3), 335-342.

Wren, F. J., Berg, E. A., Heiden, L. A., Kinnamon, C. J., Ohlson, L. A., Bridge, J. A., ... \& Bernal, M. P. (2007). Childhood anxiety in a diverse primary care population: parent-child reports, ethnicity and SCARED factor structure. Journal of the American Academy of Child \& Adolescent Psychiatry, 46(3), 332-340.

Yeguez, C. E., Page, T. F., Rey, Y., Silverman, W. K., \& Pettit, J. W. (2019). A cost analysis of a stepped care treatment approach for anxiety disorders in youth. Journal of Clinical Child and Adolescent Psychology, 1-7. 
Young, B. J., Beidel, D. C., Turner, S. M., Ammerman, R. T., McGraw, K., \& Coaston, S. C. (2006). Pretreatment attrition and childhood social phobia: Parental concerns about medication. Journal of Anxiety Disorders, 20(8), 1133-1147.

Zvielli, A., Bernstein, A., \& Koster, E. H. W. (2014). Temporal Dynamics of Attentional Bias. Clinical Psychological Science, 3(5), 772-788. doi:10.1177/2167702614551572 
VITA

\section{RAQUEL MELENDEZ}

2007-2011

2011-2012

2012-2014

2012-Present

2017-2018

2018-Present
B.A. in Psychology (with honors), summa cum laude McDaniel College

Westminster, Maryland

Program Specialist

TrueNorth Wellness Services

Hanover, Pennsylvania

M.S. in Clinical Science

Florida International University

Miami, Florida

Doctoral Candidate in Clinical Psychology

Florida International University

Miami, Florida

Predoctoral Intern

Clinical Child and Pediatric Psychology Track

University of Florida Health Science Center

Gainesville, Florida

Postdoctoral Fellow

University of Florida Division of Psychology

Gainesville, Florida

\section{SELECTED PUBLICATIONS AND PRESENTATIONS}

Bechor, M., Melendez, R., Rey, Y., Pettit, J. W., \& Silverman, W.K. (2014, November). Social Anxiety Symptoms Predict Depressive Symptoms via Attentional Control: Evidence of an Indirect Effect Among Clinic-Referred Youth. Poster presented at the Association for Behavioral and Cognitive Therapies, 2014, in Philadelphia, PA.

Buitron, V., Vaclavik, D., Melendez, R., Rey, Y., Marin, C., Silverman, W. K., \& Pettit, J. W. (2016, October). Peer-Involved Group CBT Leads to Greater Reductions in Concurrent Depressive Symptoms than Parent-Involved CBT in Children and Adolescents with Anxiety Disorders and Negative Peer Interactions. Poster presented at the Association for Behavioral and Cognitive Therapies, 2016, in New York, NY.

Melendez, R., Bechor, M., Buitron, V., Rey, Y., Pettit, J.W., \& Silverman, W.K. (2017, November). Reliability of Attentional Threat Indices and Associations with Attentional Control in Children and Adolescents with Anxiety Disorders. Poster to be presented at the Association for Behavioral and Cognitive Therapies, 2017, in San Diego, CA.

Melendez, R., Bechor, M., Rey, Y., Pettit, J. W. and Silverman, W. K. (2016). Attentional control scale for children: Factor structure and concurrent validity among children and adolescents referred for anxiety disorders. J. Clin. Psychol.. doi:10.1002/jclp.22346

Pettit, J. W., Rey, Y., Bechor, M., Melendez, R., Vaclavik, D., Buitron, V., Bar-Haim, Y., Pine, D. (2016, October). Can Less Be More? Open Trial of a Stepped Care Approach for Child and Adolescent Anxiety 
Disorders. Symposium presented at the annual meeting of the Association for Behavioral and Cognitive Therapies, 2016, in New York, NY.

Pettit, J.W., Rey, Y., Bechor, M., Melendez, R., Vaclavik, D., Buitron, V., Bar-Haim, Y., Pine, D.S., \& Silverman, W.K. (2017). Can less be more? Open trial of a stepped care approach for child and adolescent anxiety disorders. Journal of Anxiety Disorders, 51, 7-13. 